Review Paper

\title{
Fuzzy rule-based set point weighting for fuzzy PID controller
}

\author{
Pubali Mitra $^{1}$ (D) Chanchal Dey ${ }^{1}$ (D) Rajani K. Mudi ${ }^{2}$
}

Received: 13 July 2020 / Accepted: 4 May 2021

Published online: 20 May 2021

(c) The Author(s) 2021 OPEN

\begin{abstract}
The objective of this work is to design a fuzzy rule-based set point weighting mechanism for fuzzy PID (FPID) controller so that an overall improved closed-loop performance may be achieved for linear as well as nonlinear process models. Till date, tuning criteria for FPID controllers are not well defined. Trial-and-error approach is primarily adopted and it is quite time-consuming and does not always ensure improved overall closed-loop behaviour. Hence, to ascertain satisfactory closed-loop performance with an initially tuned fuzzy controller, a fuzzy rule-based set point weighting mechanism is reported here. The proposed scheme is capable of providing performance enhancement with instantaneous weighting factor calculated online for each instant based on the latest process operating conditions. The proposed methodology is capable of ascertaining acceptable performances during set point tracking as well as load recovery phases. Efficacy of the proposed scheme is verified for linear as well as nonlinear process models through simulation study along with real-time verification on servo position control in comparison with the others' reported performance augmentation schemes as well as fuzzy sliding mode control.
\end{abstract}

Keywords Fuzzy PID controller · Set point weighting · Fuzzy set point weighting · FPID enhancement · Linear and nonlinear processes $\cdot$ Real-time experimentation

\section{Introduction}

Presently, controllers with inherent intelligence are found to be recognized as a complementary to the conventional controllers in various industrial closed-loop control applications. Fuzzy logic controller (FLC) [1, 2] belongs to a class where intelligence of an expert is incorporated through appropriate framing of fuzzy rules [3]. Proper selection of scaling factors (SFs) [4] with duly chosen fuzzy rules plays a crucial role towards designing a FLC. Inappropriate choice of SFs for FLC may result unsatisfactory closed-loop performance. Till date, SFs $[5,6]$ are usually chosen through multiple attempts, i.e. by trial and error or based on optimization techniques $[7,8]$, which are not easy to deal with for obtaining the desirable closed-loop response, especially for processes with modelling error. Consequently, improperly tuned FLC may result unwanted oscillations during servo and load recovery phases which may lead to actuator saturation [9].

For restricting oscillations during set point tracking, fixed set point weighting (FSW) [10] is a well-accepted methodology for conventional PID controllers but it hardly offers any benefit during load recovery. In case of FSW, a fixed set point weighting factor (usually 0.4-0.6) [11] is incorporated with the proportional term of the PID controller [12]. It results lower overshoot but increased rise time due to relatively sluggish response. To mitigate such inadequacies of FSW, Hang and Cao [13] introduced variable set point weighting (VSW) where the set point weighting factor gets varied during set point tracking through three distinct values to restrict the overshoot without sacrificing the dynamic behaviour of the process.

Pubali Mitra, pubali.mitra.cu@gmail.com; Chanchal Dey, cdaphy@caluniv.ac.in; Rajani K. Mudi, rkmudi@yahoo.com | ${ }^{1}$ University of Calcutta, Kolkata, India. ${ }^{2}$ Jadavpur University, Kolkata, India.

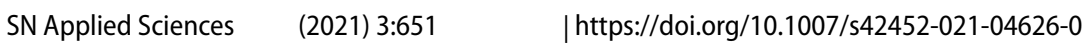


However, VSW technique [13] is incompetent to provide any improvement during load rejection phase. For higherorder linear and nonlinear processes, oscillations are truly intolerable during set point tracking and load recovery, especially in the presence of dead time. Set point weighting mechanism for nonlinear processes is reported in [14] by Mantz. Sree and Chidambaram [15] proposed integral square error (ISE)-based set point weighting scheme for unstable processes with zero. In case of integrating and time delayed unstable processes, overshoots are truly excessive, and hence, to alleviate such issues set point weighting methodologies are reported in $[16,17]$.

To ensure acceptable performance during transient phases, fuzzy logic-based set point weighting with conventional PID controller is proposed by Visioli [18] where the weighting factor for the proportional term is calculated with the help of fuzzy rules. Later, another effective weighting strategy known as dynamic set point weighting (DSW) for PID controllers is reported in $[19,20]$ where the weighting factor is varied depending on the current process operating conditions and hence capable of providing an overall performance enhancement. To overcome the limitation of improper tuning for fuzzy controller which results undesired oscillations during closed-loop operation, dynamic set point weighting (DSW) mechanism [21-23] is incorporated while designing the FLC. DSW technique is capable of ensuring lesser oscillations while tracking new set value and faster load recovery. However, the DSW methodology is not quite straightforward to employ in real-time applications.

Here, the idea of dynamic set point weighting is realized with the help of heuristic fuzzy rules. Knowledge of an experienced process operator is utilized for designing the fuzzy rule base which provides the suitable value for set point weighting factor depending on the current process operating conditions. A set of nine predefined fuzzy rules are framed here to provide the appropriate weighting factor $\left(\beta_{\mathrm{fu}}\right)$ for the fuzzy PID controller based on the current change of error $(\Delta e)$ calculated from the recent process output. Superiority of the proposed fuzzy set point weighting mechanism for the fuzzy PID controller (FSWFPID) is established by comparing its performance with conventional fuzzy PID (FPID) [4] controllers as well as other performance augmentation schemes reported for FPID controllers like self-tuning fuzzy PID (STFPID) [24, 25], dynamic set point weighting fuzzy PID (DSWFPID) [21] and fuzzy sliding mode controllers (FSMC) [26-28]. Superiority of the proposed FSWFPID is verified for integrating second-order and higher-order linear and nonlinear processes as they provide large oscillations in the presence of dead time. To have quantitative performance estimation for the reported controllers, a list of performance indicespercentage overshoot $(\% \mathrm{OS})$, rise time $\left(t_{r}\right)$, settling time $\left(t_{s}\right)$, integral absolute error (IAE), integral time absolute error (ITAE) and total variation in control action (TV) are evaluated for each setting separately. In addition to closed-loop performance analysis, robustness of the proposed controller is also studied with parametric variations in dead time and in the presence of measurement noise. Apart from simulation study, real-time validation is made on a DC servo position control unit.

\section{Proposed controller design}

In this section, detailed structure of the proposed fuzzy rule-based set point weighted fuzzy PID controller (FSWFPID) is described. Figure 1a shows the block diagram of the FSWFPID with two inputs-weighted error $\left(e_{\mathrm{fw}}\right)$ and change of error $(\Delta e)$, and two outputs-normalized control action $\left(u_{N}\right)$ and its incremental value $\left(\Delta u_{N}\right)$. For simplicity, fuzzy PI (FPI) and fuzzy PD (FPD) controllers are combined together to realize the fuzzy PID (FPID) controller. Benefit of this structure is that both FPI and FPD controllers share the common control rule base (CRB) and input $\mathrm{SFs}\left(\mathrm{G}_{e}, \mathrm{G}_{\Delta e}\right)$, only the output $\mathrm{SFs}\left(G_{u}, G_{\Delta u}\right)$ are different. For the FPI, output $S F$ is $G_{\Delta u}$ whereas for the FPD it is $G_{u}$. All the normalized inputs $\left(e_{N}, \Delta e_{N}\right)$ and outputs $\left(u_{N}, \Delta u_{N}\right)$ of FSWFPID are defined over the common normalized domain $-1-+1$. Two distinct sets of membership functions (MFs) with 7 and 5 input-output fuzzy sets are considered with 49 and 25 control rules. To avoid the need of any prior knowledge, both the control rule bases (CRB) consisting of 49 and 25 rules are designed with unbiased choice of MFs - symmetric triangles with equal base and $50 \%$ overlap with adjacent MFs as shown in Fig. $1 \mathrm{~b}$ and $d$, respectively. Corresponding rule surfaces are shown in Fig. 1c and e which are found to be highly nonlinear in nature. Here, $u_{N}$ is the normalized output of FPD and the same is also considered as the incremental normalized output $\left(\Delta u_{N}\right)$ for FPI.

In case of proposed fuzzy controller Mamdani type fuzzy inferencing [4] is employed. It is observed that the design method of a typical Mamdani fuzzy controller [1] is similar as sliding mode fuzzy controller where the diagonal form of CRB is treated as sliding (switching) line and the magnitude of specific positive or negative fuzzy value of control action $(u)$ is determined on the basis of the distance between its corresponding state vector $(e)$ and the sliding line. Hence, the control rule bases (CRB) of the proposed fuzzy controller (with 49 and 25 rules) are designed following the concept of sliding mode principle [29]. This rule generation technique is quite simple and straightforward. Consequent part of the entire rule base can easily be obtained through a simple calculation based on their respective position in the rule table using the following principle-with seven 


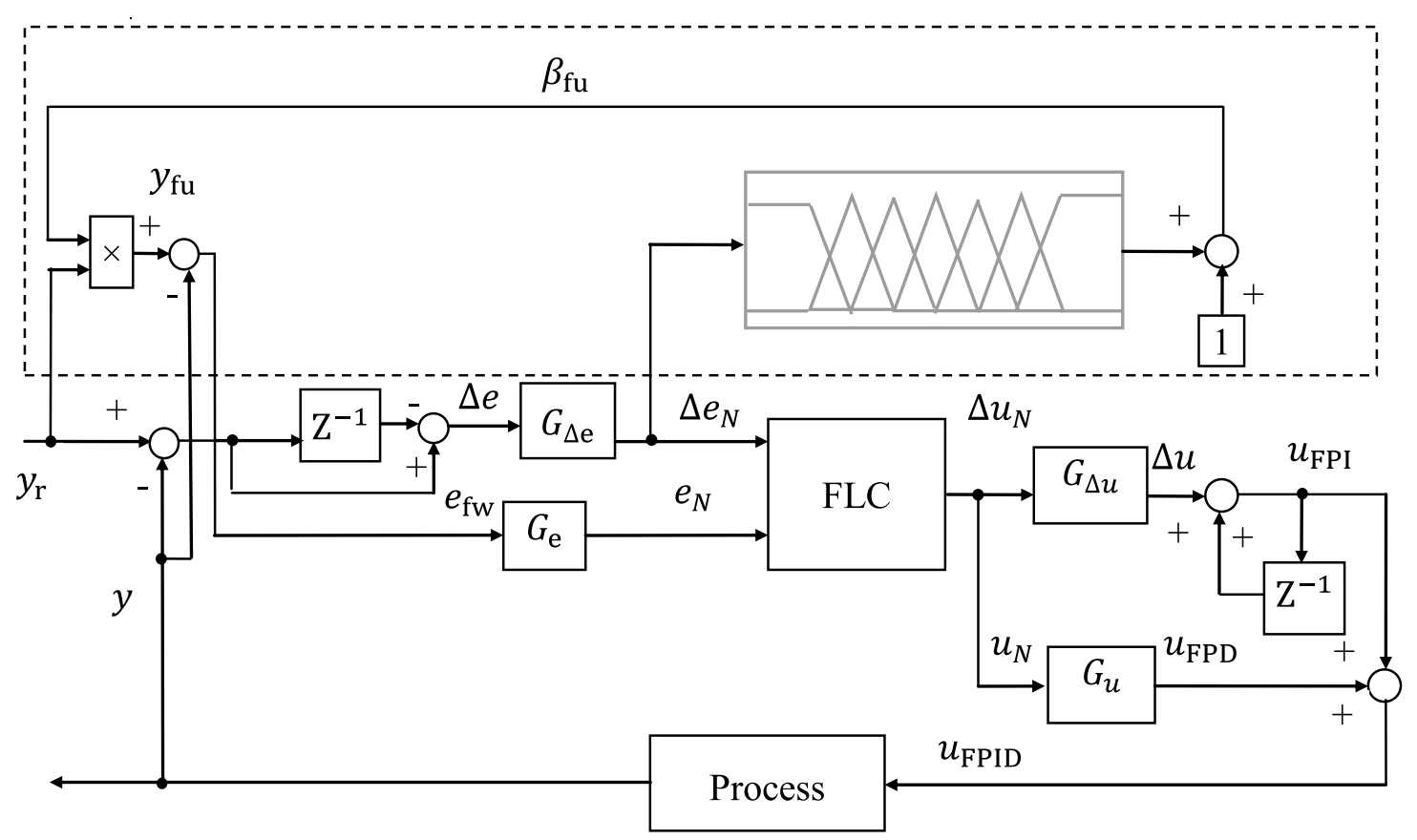

(a)

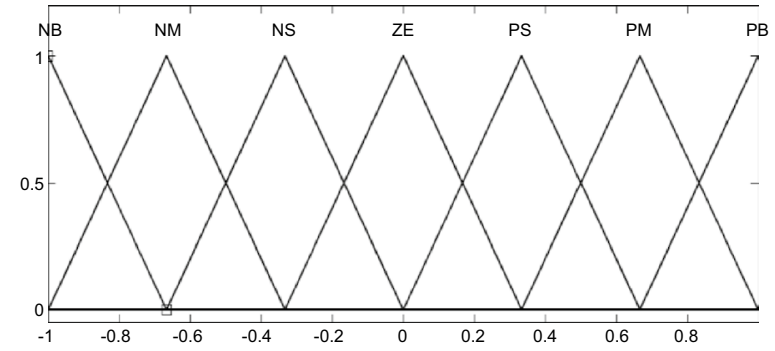

(b)

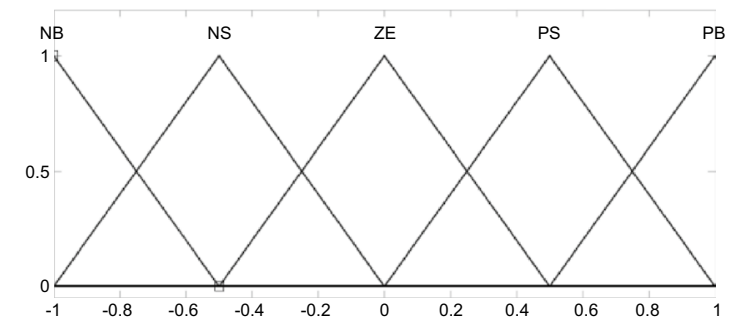

(d)

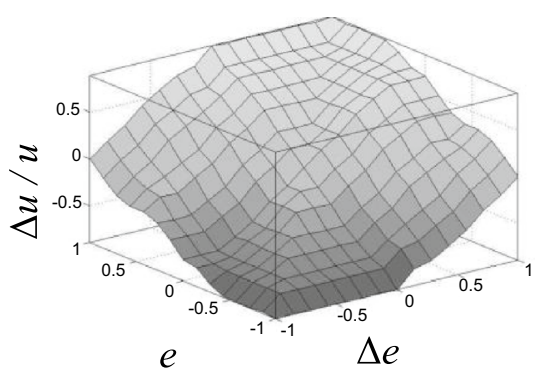

(c)

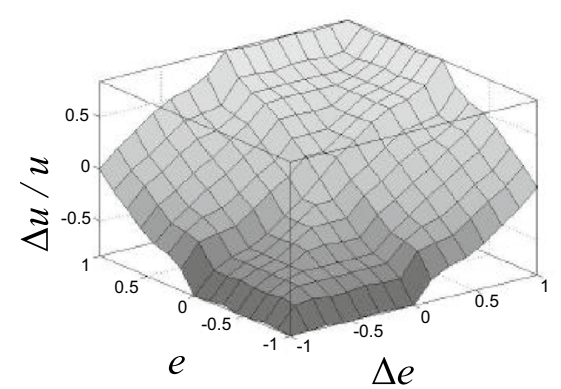

(e)

Fig. 1 a Block diagram of the proposed fuzzy PID controller with fuzzy set point weighting (FSWFPID) b 7 MFs for input ( $e_{N}, \Delta e_{N}$ ) and output $\left(u_{N}, \Delta u_{N}\right)$ variables $\mathbf{c}$ Control surface with 49 rules $\mathbf{d} 5 \mathrm{MFs}$ for input $\left(e_{N}, \Delta e_{N}\right)$ and output $\left(u_{N}, \Delta u_{N}\right)$ variables e Control surface with 25 rules 
fuzzy partitions of the universe of discourse related to input $(e, \Delta e)$ and output $(\Delta u, u)$ variables, we have 7 fuzzy sets, i.e. $N=7$ and these fuzzy sets can be termed as: $-3(N B)$, -2 (NM), -1 (NS), 0 (ZE), 1 (PS), 2 (PM), 3(PB). Similarly, with five fuzzy partitions, i.e. $N=5$, fuzzy sets can be termed as: -2 (NB), -1 (NS), 0 (ZE), 1 (PS), 2 (PB). corresponding to $e_{N}, \Delta e_{N}$ and $\Delta u_{N}$ or $u_{N}$ may be indexed as $i, j$, and $k$, respectively, where $i, j$, and $k$ have index values $(-N+1) / 2,(-N+3) / 2, \ldots \ldots .-1,0,1, \ldots \ldots,(N-3) / 2,(N-1) / 2$ for $N$ (odd) number of fuzzy partitions. Consequently, a rule $R_{(i j, k)}$ is framed for the input combination of fuzzy sets $i$ and $j$ (antecedent) with the output fuzzy set $k$ (consequent), obtained by the following relation:

If $\left|\left\{\mu_{e}(i)+\mu_{\Delta e}(j)\right\}\right|<\left(\frac{N-1}{2}\right)$ Then $R_{\mu}[e(i), \Delta e(j)]=\left\{\mu_{e}(i)+\mu_{\Delta e}(j)\right\}$

Else If $\left|\left\{\mu_{e}(i)+\mu_{\Delta e}(j)\right\}\right| \geq\left(\frac{N-1}{2}\right)$ Then $R_{\mu}[e(i), \Delta e(j)]=\operatorname{Sgn}\left\{\mu_{e}(i)+\mu_{\Delta e}(j)\right\}\left(\frac{N-1}{2}\right)$.

\subsection{Fuzzy rule generation}

Fuzzy PID (FPID) controller can be realized by parallel operation of FPI and FPD controllers which share the common control rule base (CRB), and is designed with 49 and 25 'If-Then' rules as shown in Fig. $2 a$ and b, respectively. For FPI controller, rules have the form 'If $e$ is $E$ and $\Delta e$ is $\Delta E$ Then $\Delta u$ is $\Delta U^{\prime}$ and similarly, for PD type FLC (FPD) the rules have the form 'If $e$ is $E$ and $\Delta e$ is $\Delta E$ Then $u$ is $U$ '. Fuzzy partitions are recognized with term sets $\{N B$, NM, NS, ZE, PS, PM, PB\} as shown in Fig. 1b. Fuzzy sets
As an example, due to 7 fuzzy partitions $(N=7)$ for a given input combination $\left(e_{N}, \Delta e_{N}\right)=(\mathrm{PM}, \mathrm{NB})$, i.e. $(i, j)=(2,-3)$ the output fuzzy set according to Eq. (1) is given by $k=i+j=2+(-3)=-1$, i.e. NS $\left(\right.$ as $\left.|i+j|<\left(\frac{N-1}{2}\right)\right)$. Therefore, the corresponding rule is $R_{(i j, k)}=R_{(2-3,-1)}=R_{(\mathrm{PM} \mathrm{NB}, \mathrm{NS})}$ : 'If $e$ is $\mathrm{PM}$ and $\Delta e$ is NB Then $\Delta u$ or $u$ is NS'. Considering another input combination $\left(e_{N}, \Delta e_{N}\right)=(\mathrm{PB}, \mathrm{PB})$, i.e. $(i, j)=(3,3)$ the output fuzzy set $k=\operatorname{Sgn}\left\{\mu_{\mathrm{e}}(i)+\mu_{\Delta e}(j)\right\}\left(\frac{N-1}{2}\right)=\frac{7-1}{2}=3$, i.e. $\operatorname{PB}\left(\operatorname{as}|i+j| \geq \frac{N-1}{2}\right)$. Hence, the corresponding rule is $R_{(i j, k)}=R_{(33,3)}=R_{(\mathrm{PB} \mathrm{PB}, \mathrm{PB})}$ :

\begin{tabular}{|c|c|c|c|c|c|c|c|c|}
\hline$\Delta e / e$ & $\mathrm{NB}^{(-3)}$ & $\mathbf{N M}^{(-2)}$ & $\mathbf{N S ^ { ( - 1 ) }}$ & $\mathbf{Z} \mathbf{E}^{(0)}$ & $\mathbf{P S}^{(1)}$ & $\mathbf{P M}^{(2)}$ & $\mathbf{P B}^{(3)}$ & \multirow{5}{*}{$\begin{array}{c}\text { If }\left|\left\{\mu_{e}(i)+\mu_{\Delta e}(j)\right\}\right|<\left(\frac{N-1}{2}\right) \\
\text { Then } R_{\mu}[e(i), \Delta e(j)]=\left\{\mu_{e}(i)+\mu_{\Delta e}(j)\right\} \\
\text { Rule 6: } R_{6}=\left\{\mu_{e}(N B)+\mu_{\Delta e}(P M)\right\}=(-3)+2=-1 \\
\Rightarrow R_{6}=N S\end{array}$} \\
\hline $\mathrm{NB}^{(-3)}$ & $\mathrm{NB}_{(\mathrm{R} 1)}$ & $\mathrm{NB}_{(\mathrm{R} 2)}$ & $\mathrm{NB}_{(\mathrm{R} 3)}$ & $\mathrm{NB}_{(\mathrm{R} 4)}$ & $\mathrm{NM}_{(\mathrm{R} 5)}$ & $\mathrm{NS}_{(\mathrm{R} 6)}$ & $\mathrm{ZE}_{(\mathrm{R} 7)}$ & \\
\hline $\mathbf{N} \mathbf{M}^{(-2)}$ & $\mathrm{NB}_{(\mathrm{R} 14)}$ & $\mathrm{NB}_{(\mathrm{R} 13)}$ & $\mathrm{NM}_{(\mathrm{R} 12)}$ & $\mathrm{NM}_{(\mathrm{R} 11)}$ & $\mathrm{NS}_{(\mathrm{R} 10)}$ & $\mathrm{ZE}_{(\mathrm{R} 9)}$ & $\mathrm{PS}_{(\mathrm{R} 8)}$ & \\
\hline $\mathbf{N S}^{(-1)}$ & $\mathrm{NB}_{(\mathrm{R} 15)}$ & $\mathrm{NM}_{(\mathrm{R} 16)}$ & $\mathrm{NM}_{(\mathrm{R} 17)}$ & $\mathrm{NS}_{(\mathrm{R} 18)}$ & $\mathrm{ZE}_{(\mathrm{R} 19)}$ & $\mathrm{PS}_{(\mathrm{R} 20)}$ & $\mathrm{PM}_{(\mathrm{R} 21)}$ & \\
\hline $\mathbf{Z E} \mathbf{E}^{(0)}$ & $\mathrm{NB}_{(\mathrm{R} 28)}$ & $\mathrm{NM}_{(\mathrm{R} 27)}$ & $\mathrm{NS}_{(\mathrm{R} 26)}$ & $\mathrm{ZE}_{(\mathrm{R} 25)}$ & $\mathrm{PS}_{(\mathrm{R} 24)}$ & $\mathrm{PM}_{(\mathrm{R} 23)}$ & $\mathrm{PB}_{(\mathrm{R} 22)}$ & \\
\hline $\mathbf{P S}^{(\mathbf{1})}$ & $\mathrm{NM}_{(\mathrm{R} 29)}$ & $\mathrm{NS}_{(\mathrm{R} 30)}$ & $\mathrm{ZE}_{(\mathrm{R} 31)}$ & $\mathrm{PS}_{(\mathrm{R} 32)}$ & $\mathrm{PM}_{(\mathrm{R} 33)}$ & $\mathrm{PM}_{(\mathrm{R} 34)}$ & $\mathrm{PB}_{(\mathrm{R} 35)}$ & \\
\hline $\mathbf{P M}^{(2)}$ & $\mathrm{NS}_{(\mathrm{R} 42)}$ & $\mathrm{ZE}_{(\mathrm{R} 41)}$ & $\mathrm{PS}_{(\mathrm{R} 40)}$ & $\mathrm{PM}_{(\mathrm{R} 39)}$ & $\mathrm{PM}_{(\mathrm{R} 38)}$ & $\mathrm{PB}_{(\mathrm{R} 37)}$ & $\mathrm{PB}_{(\mathrm{R} 36)}$ & If $\left|\left\{\mu_{e}(i)+\mu_{\Delta e}(j)\right\}\right|>\left(\frac{N-1}{2}\right)$ \\
\hline $\mathbf{P B}^{(3)}$ & $\mathrm{ZE}_{(\mathrm{R} 43)}$ & $\mathrm{PS}_{(\mathrm{R} 44)}$ & $\mathrm{PM}_{(\mathrm{R} 45)}$ & $\mathrm{PB}_{(\mathrm{R} 46)}$ & $\mathrm{PB}_{(\mathrm{R} 47)}$ & $\mathrm{PB}_{(\mathrm{R} 48)}$ & $\mathrm{PB}_{(\mathrm{R} 49)}$ & Then $R_{\mu}[e(i), \Delta e(j)]=\operatorname{Sgn}\left\{\mu_{e}(i)+\mu_{\Delta e}(j)\right\}\left(\frac{N-1}{2}\right)$ \\
\hline & & & & & & & & $\begin{array}{c}\text { Rule 49: } \mathrm{R}_{49}=\operatorname{Sgn}\left\{\mu_{e}(\mathrm{~PB})+\mu_{\Delta e}(\mathrm{~PB})\right\}\left(\frac{7-1}{2}\right)=3 \\
\Rightarrow \mathrm{R}_{49}=\mathrm{PB}\end{array}$ \\
\hline
\end{tabular}

(a)

\begin{tabular}{|c|c|c|c|c|c|c|}
\hline$\Delta e / e$ & $\mathbf{N B}^{(-2)}$ & $\mathbf{N M}^{(-1)}$ & $\mathbf{Z} \mathbf{E}^{(0)}$ & $\mathbf{P} \mathbf{M}^{(\mathbf{1})}$ & $\mathbf{P B}^{(2)}$ & If $\left|\left\{\mu_{e}(i)+\mu_{\Delta e}(j)\right\}\right|=\left(\frac{N-1}{2}\right)$ \\
\hline $\mathbf{N B}^{(-2)}$ & $\mathrm{NB}_{(\mathrm{R} 1)}$ & $\mathrm{NB}_{(\mathrm{R} 2)}$ & $\mathrm{NB}_{(\mathrm{R} 3)}$ & $\mathrm{NM}_{(\mathrm{R} 4)}$ & $\mathrm{ZE}_{(\mathrm{R} 5)}$ & Then $R_{\mu}[e(i), \Delta e(j)]=\operatorname{Sgn}\left\{\mu_{e}(i)+\mu_{\Delta e}(j)\right\}\left(\frac{N-1}{2}\right)$ \\
\hline $\mathbf{N} \mathbf{M}^{(-1)}$ & $\mathrm{NB}_{(\mathrm{R} 10)}$ & $\mathrm{NB}_{(\mathrm{R} 9)}$ & $\mathrm{NM}_{(\mathrm{R} 8)}$ & $\mathrm{ZE}_{(\mathrm{R} 7)}$ & $\mathrm{PM}_{(\mathrm{R} 6)}$ & \\
\hline $\mathbf{Z E}^{(0)}$ & $\mathrm{NB}_{(\mathrm{R} 11)}$ & $\mathrm{NM}_{(\mathrm{R} 12)}$ & $\mathrm{ZE}_{(\mathrm{R} 13)}$ & $\mathrm{PM}_{(\mathrm{R} 14)}$ & $\mathrm{PB}_{(\mathrm{R} 15)}$ & Rule 15: $\mathrm{R}_{15}=\operatorname{Sgn}\left\{\mu_{e}(\mathrm{ZE})+\mu_{\Delta e}(\mathrm{~PB})\right\}\left(\frac{5-1}{2}\right)=2$ \\
\hline $\mathbf{P} \mathbf{M}^{(\mathbf{1})}$ & $\mathrm{NM}_{(\mathrm{R} 16)}$ & $\mathrm{ZE}_{(\mathrm{R} 17)}$ & $\mathrm{PM}_{(\mathrm{R} 18)}$ & $\mathrm{PB}_{(\mathrm{R} 19)}$ & $\mathrm{PB}_{(\mathrm{R} 20)}$ & $\Rightarrow \mathrm{R}_{15}=\mathrm{PB}$ \\
\hline $\mathbf{P B}^{(2)}$ & $\mathrm{ZE}_{(\mathrm{R} 21)}$ & $\mathrm{PM}_{(\mathrm{R} 22)}$ & $\mathrm{PB}_{(\mathrm{R} 23)}$ & $\mathrm{PB}_{(\mathrm{R} 24)}$ & $\mathrm{PB}_{(\mathrm{R} 25)}$ & \\
\hline
\end{tabular}

(b)

Fig. 2 Rule bases for computation of $\Delta u / u$ with a 49 rules, $\mathbf{b} 25$ rules, and the corresponding rule generation schemes 
'If $e$ is PB and $\Delta e$ is PB Then $\Delta u$ or $u$ is PB'. Hence, 49 fuzzy rules with 7 fuzzy partitions (i.e. for $N=7$ ) are depicted in Fig. 2a. Likewise, with five fuzzy partitions (i.e. for $N=5$ ) 25 rules may be framed [21] as shown in Fig. 2 b.

\subsection{Realization of the proposed controller}

Figure 1a shows the block diagram of the proposed controller where the input variables are weighted error $\left(e_{\mathrm{fw}}\right)$ and change of error $(\Delta e)$ with $\mathrm{SFs}_{e}$ and $G_{\Delta e}$

$e_{N}=G_{e} e_{\mathrm{fw}}=G_{e}\left(y_{\mathrm{fu}}-y\right)$,

$\Delta e_{N}=G_{\Delta e} \Delta e=G_{\Delta e}(e(k)-e(k-1))$.

In Eq. (2), the weighted error $e_{\mathrm{fw}}$ is $\left(y_{\mathrm{fu}}-y\right)$ where $y_{\mathrm{fu}}$ is the fuzzy rule-based weighted set point (Fig. 3). The weighted error $e_{\mathrm{fw}}$ is normalized $\left(e_{N}\right)$ through multiplication with the input scaling factor $G_{e}$. Similarly, in Eq. (3) $\Delta e_{N}$ is obtained by multiplying $\Delta e$ with $G_{\Delta e}$ and both the normalized inputs $\left(e_{N}, \Delta e_{N}\right)$ are fed to the fuzzy inference block. Similarly, output variables $(u, \Delta u)$ are given by

$u=G_{u} u_{N}$

$\Delta u=G_{\Delta u} \Delta u_{N}$

$u(k)=u(k-1)+\Delta u(k)$.

For realizing the control action of FPI, additional integrator block is required as shown in Fig. 1a. Fuzzy PID control action $\left(u_{F P I D}\right)$ is obtained by combining the weighted outputs of FPI $\left(u_{\mathrm{FPI}}\right)$ and FPD $\left(u_{\mathrm{FPD}}\right)$ as given by Eq. (7).
$u_{\mathrm{FPID}}=u_{\mathrm{FPI}}+u_{\mathrm{FPD}}$.

For the FPI, incremental control output can be expressed by

$\Delta u_{\mathrm{FPI}}(K)=G_{\Delta u} f\left(e_{N}, \Delta e_{N}\right)=G_{\Delta u} f\left(G_{e} e, G_{\Delta e} \Delta e\right)$

The nonlinear function $f$ denotes the rule base mapping between input-output variables. Similarly, for the fuzzy PD controller (FPD) approximated linear expression of the controller output can be written as

$\Delta u_{\mathrm{FPD}}(k)=G_{\mathrm{u}} f\left(G_{e} e, G_{\Delta e} \Delta e\right)$.

Now, if $\Delta t$ is the sampling interval then from Eq. (7) approximated linear expression of the control signal for the fuzzy PID controller (FPID) [21] at a time instant $n$ can be written as

$$
\begin{aligned}
u_{\mathrm{FPID}}(n)= & u_{\mathrm{FPI}}(n)+u_{\mathrm{FPD}}(n) \\
= & \sum_{j=1}^{n}\left\{G_{\Delta u} G_{e} e(j), G_{\Delta u} G_{\Delta e} \Delta e(j)\right\} \Delta t \\
& +\left\{G_{u} G_{e} e(n), G_{u} G_{\Delta e} \Delta e(n)\right\} .
\end{aligned}
$$

Now, for the proposed FSWFPID, both the error signals are involved in Eq. (10) of fuzzy PI and fuzzy PD controllers, control action is computed based on fuzzy rules with set point weighting mechanism and hence it can be expressed as.

$$
\begin{aligned}
u_{\mathrm{FPID}}(n)= & \sum_{j=1}^{n}\left[G_{\Delta u} G_{e}\left\{\beta_{\mathrm{fu}}(j) y_{r}-y(j)\right\},\right. \\
& \left.G_{\Delta u} G_{\Delta e} \Delta e(j)\right] \Delta t \\
& +\left[G_{u} G_{e}\left\{\beta_{\mathrm{fu}}(n) y_{r}-\mathrm{y}(n)\right\}, G_{u} G_{\Delta e} \Delta e(n)\right] .
\end{aligned}
$$

Fig. $39 \mathrm{MFs}$ for input variable $(\Delta e)$ and output variable $\left(\beta_{\mathrm{fu}}\right)$

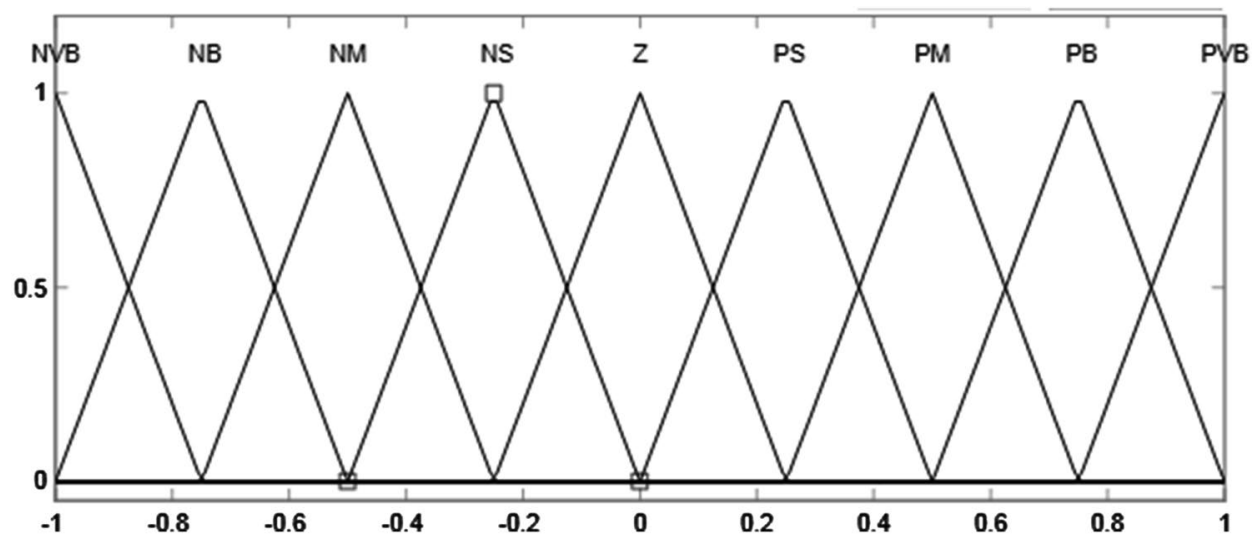

Table 1 Nine fuzzy rules 

linguistic variables used in fuzzy inference system
Table 2 Meaning of the

\begin{tabular}{ll}
\hline NVB & Negative Very Big \\
\hline NB & Negative big \\
NM & Negative medium \\
NS & Negative small \\
$Z$ & Zero \\
PS & Positive small \\
PM & Positive medium \\
PB & Positive big \\
PVB & Positive very big \\
\hline
\end{tabular}

$$
\begin{aligned}
\operatorname{or} u_{\mathrm{FPID}}(n)= & \sum_{j=1}^{n} G_{\Delta u} G_{e}\left[\left\{y_{\mathrm{fu}}(j)-y(j)\right\}+\Delta e(j)\right] \Delta t \\
& +G_{u} G_{e}\left[\left\{y_{\mathrm{fu}}(n)-y(n)\right\}+\Delta e(n)\right] .
\end{aligned}
$$

In Eq. (11), $y_{\mathrm{r}}$ is the set point and $\beta_{\mathrm{fu}}$ is the weighting factor which is computed with the help of 9 fuzzy rules as shown in Table 1. MFs are realized by 9 symmetric triangles having equal base and $50 \%$ overlap defined over the normalized range $[-1,+1]$ and meaning of the input-output linguistic variables for MFs are listed in Table 2. Fuzzy rule-based weighting factor $\beta_{\mathrm{fu}}$ is calculated based on the current value of normalized change of error $\left(\Delta e_{N}\right)$. To calculate the appropriate value of the weighting factor, the weighting parameter is added (Fig. 1a) to a constant value (unity) and the resulting weighting factor is employed to obtain the weighted set point as given by Eq. (13)

$y_{\mathrm{fu}}(k)=\beta_{\mathrm{fu}}(k) \times y_{r}$.
Table 3 Variation of weighting factor and related control action

\begin{tabular}{llll}
\hline $\begin{array}{l}\text { Sign of } \\
\text { change of } \\
\text { error }(\Delta e)\end{array}$ & $\begin{array}{l}\text { Value of fuzzy } \\
\text { logic-based } \\
\text { weighted set } \\
\text { point }\left(y_{\mathrm{fu}}\right)\end{array}$ & $\begin{array}{l}\text { Value of fuzzy } \\
\text { logic-based } \\
\text { weighted set } \\
\text { point factor } \\
\left(\beta_{\mathrm{fu}}\right)\end{array}$ & $\begin{array}{l}\text { Value of } \\
\text { weighted } \\
\text { control action } \\
\left(u_{w}\right)\end{array}$ \\
\hline $\mathrm{A} \quad-\mathrm{ve}$ & $<y_{r}$ & $<1$ & $<u$ \\
$\mathrm{~B} \quad-\mathrm{ve}$ & $<y_{r}$ & $<1$ & $<u$ \\
$\mathrm{C} \quad+$ ve & $>y_{r}$ & $>1$ & $>u$ \\
$\mathrm{D} \quad+$ ve & $>y_{r}$ & $>1$ & $>u$
\end{tabular}

\section{Control strategy}

The objective of the proposed FSWFPID is to ascertain that the oscillations must remain within the acceptable limit for an initially designed fuzzy controller. To achieve this goal, weighting factor $\beta_{\mathrm{fu}}$ gets varied online depending on the current change of error $(\Delta e)$ of the process variable. For better understanding of the online weighting mechanism, a typical closed-loop response depicting set point change followed by load disturbance along with its corresponding variation of $\Delta e$ and $\beta_{\mathrm{fu}}$ is shown in Fig. 4.

(i) Subsequent to a unit step change as input, controlled variable will be smaller than the set value, i.e. $y<y_{r}$ and process output is moving towards the set value as shown by the arrowhead at the operating point A of Fig. 4. Under such operating condition, proportional action of the fuzzy control-
Fig. 4 Typical closed-loop response under set point change and subsequent load variation with change of error $(\Delta e)$ and weighting factor $\left(\beta_{\mathrm{fu}}\right)$

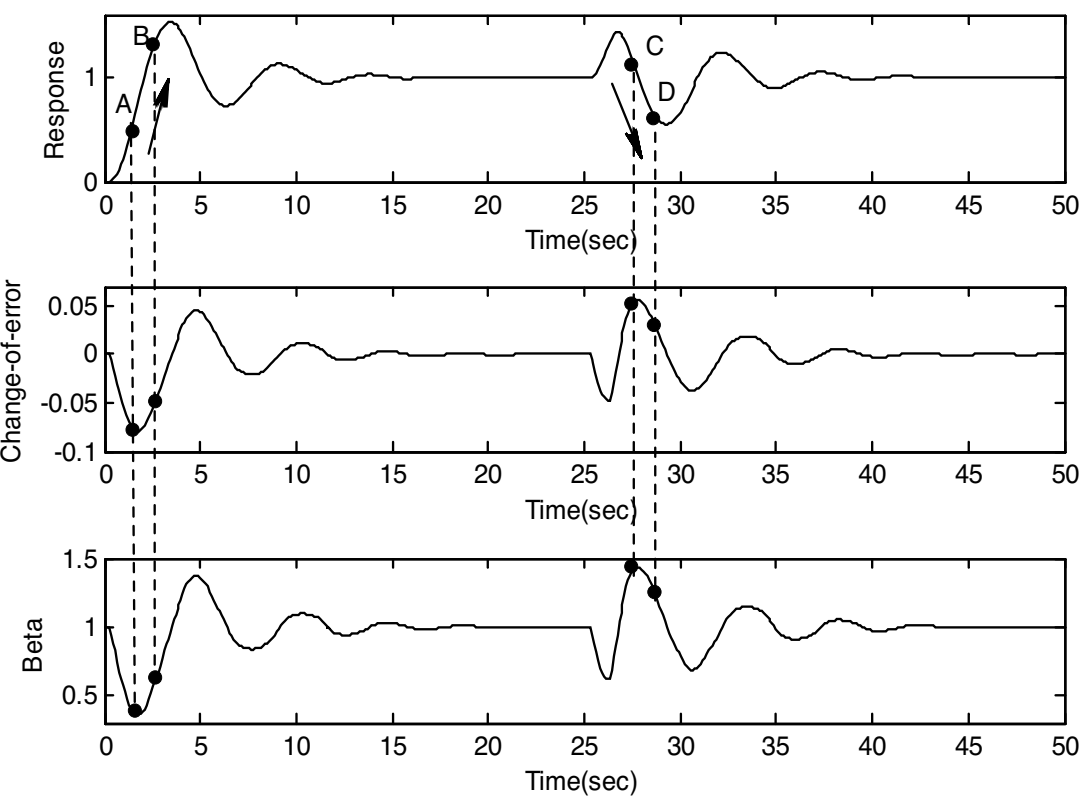


ler should be reduced to restrict the possible overshoot in the subsequent operating phase. Here, $\Delta e_{r}$ is negative, hence $\beta_{\mathrm{fu}}<1.0$ which results the weighted set point $y_{\mathrm{fu}}<y_{r}$ as depicted in Table 3 , i.e. $\left(y_{\mathrm{fu}}-y\right)<\left(y_{r}-y\right)$, thereby resulting weaker proportional action for FSWFPID compared to conventional FPID. Thus, the proposed scheme is capable of producing appropriate control action required to reduce the possible subsequent overshoot.

(ii) As the controlled variable exceeds the desired value (point B of Fig. 4), i.e. $y>y_{r}$ and is moving further away from it, proportional action of the controller should strengthen up to restrict this diverging nature of the controlled variable. Consequently, control action should be strong enough to bring the controlled variable quickly back to its desired value. Under such circumstances, $\Delta e_{r}$ is negative, so $y_{\mathrm{fu}}<y_{r}$ as $\beta_{\mathrm{fu}}<1.0$ (i.e. $\left(y_{\mathrm{fu}}-y\right)>\left(y_{r}-y\right)$ ) as the current controlled variable gets further separated from $y_{\mathrm{fu}}$ than the deviation from $y_{r}$. Hence, the resultant proportional action of FSWFPID becomes stronger than FPID which provides faster convergence of the process by restricting further deviation of the controlled variable.

(iii) After having overshoot, as process variable is moving rapidly towards the set point, there is a possibility of large undershoots in subsequent duration. Such situation is depicted by point $C$ of Fig. 4 where $y>y_{r}$. Under such circumstances, strength of proportional action for fuzzy controller needs to be reduced to restrict the possible undershoots. Here, $\Delta e_{r}$ is positive resulting $\beta_{\mathrm{fu}}>1.0$ and hence $y_{\mathrm{fu}}>y_{r}$ and $\left(y_{\mathrm{fu}}-y\right)<\left(y_{r}-y\right)$. Therefore, FSWFPID results relatively softer proportional action which helps to reduce undershoots compared to the conventional FPID in subsequent operating phase.

(iv) During downward movement of the controlled variable as shown by the point $D$ of Fig. 4 where the process is moving away from the set value, required control action from the fuzzy controller should be dominant enough to restrict the possible undershoot. In such situation, $\Delta e_{r}$ is positive which results $\beta_{\mathrm{fu}}>1.0$, hence $y_{\mathrm{fu}}>y_{r}$ and $\left(y_{\mathrm{fu}}-y\right)>\left(y_{r}-y\right)$. Hence, the resultant proportional action of FSWFPID will be stronger than FPID and the overall con- trol action becomes more aggressive to restrict the possible undershoots in the subsequent phases.

Hence, from the above discussions it is quite evident that the proposed fuzzy rule-based set point weighting mechanism for fuzzy PID controller (FSWFPID) is capable of providing suitable variation of control action which is expected to enhance the closed-loop performance of an initially tuned conventional fuzzy PID controller (FPID) during both the set point tracking and load rejection phases.

\section{Performance analysis}

In this section, performance of the proposed controller is evaluated through simulation study as well as real-time experimentation. Five well-known linear and nonlinear process models [12, 13, 18, 19, 20, 21, 24, 27, 28 and 29] are considered in the simulation study. The performances of the proposed FSWFPID are compared with conventional FPID and other reported fuzzy controllers, i.e. STFPID [24, 25] and DSWFPID [21]. In addition, performance comparison is also made with fuzzy sliding mode control (FSMC) [26-28]. FSMC has proved its robustness against variation in process dynamics and external disturbances. The sliding surface of FSMC is considered in Eq. (14) where $\gamma$ is the surface parameter.

$s=\dot{e}+\gamma e$.

Each process model is tested with same step set point change as well as impulse/step load disturbance. For comparison, percentage overshoot $(\% O S)$, rise time $\left(t_{r}\right)$, settling time $\left(t_{s}\right)$, integral absolute error (IAE), integral time absolute error (ITAE) and total variantion in control action (TV) are considered as performance indices. To establish the robustness of the proposed scheme same set of SFs, MFs and control rule bases are considered for all processes with separate values of dead time. In all cases, Mamdani type inferencing and centroid method of defuzzification is employed. For the neumerical integration Runga-Kutta fourth-order method [30] is considered and sampling time is taken as $0.1 \mathrm{~s}$. Identical setting is also adopted during real-time evaluation with Quanser QUBE-Servo 2 [31] during servo tracking as well as load variations. Here, it is to mention that FSMC technique is basically PD controller by nature and hence suitable only for integrating processes. 
Fig. 5 Responses and control actions for Model I using 49 rules during set point response and with load variation for a $L=0.05 \mathrm{~s}, \mathbf{b} L=0.3 \mathrm{~s}$
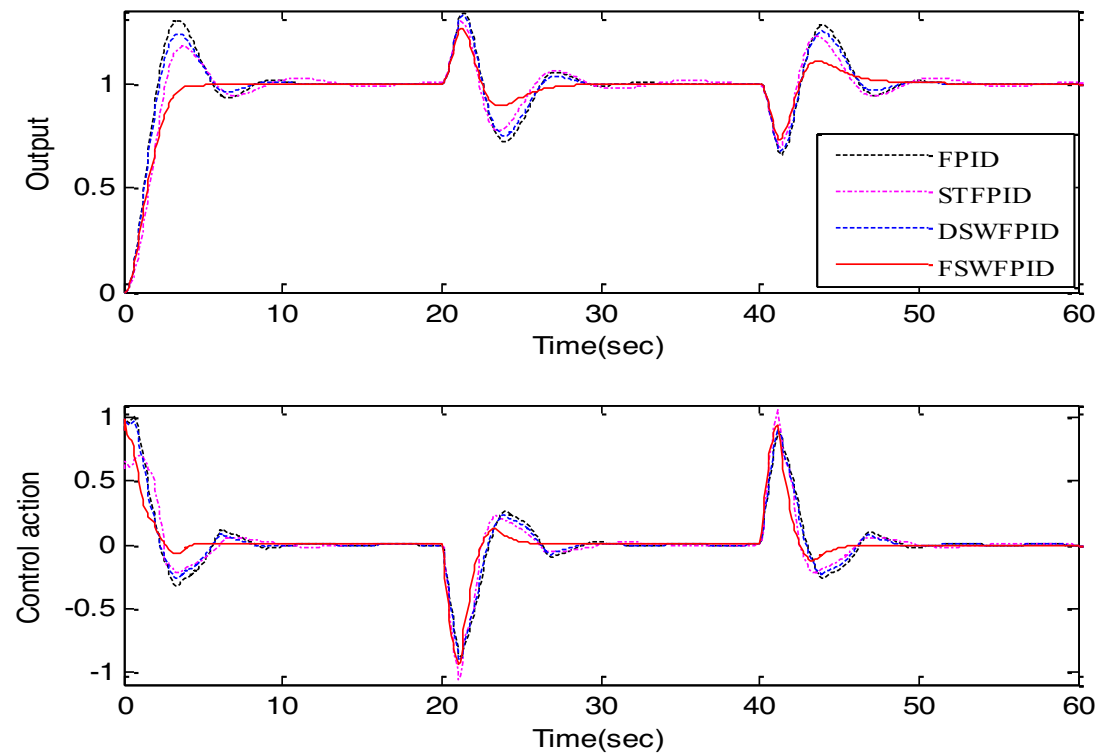

(a)
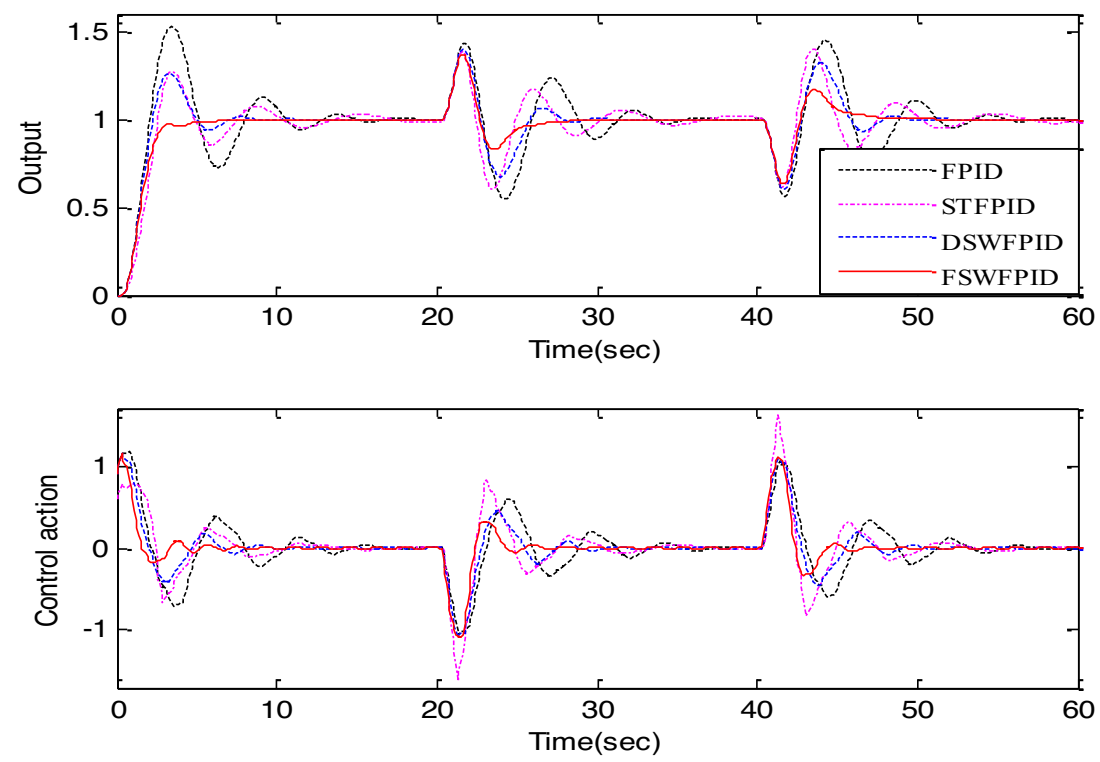

(b)

\subsection{Simulation study}

\subsubsection{Model I: Integrating second-order plus dead time (ISOPDT) process [12, 18-21]}

Integrating second-order plus dead time (ISOPDT) model is considered as given by Eq. (15)

$G_{1}(s)=\frac{K e^{-L s}}{s(\tau s+1)}$
This process is also known as marginally stable process as one of its poles is at the origin and the presence of the dead time results difficulty in controlling the system. Here, $K$ is open-loop gain, $\tau$ is the time constant, and $L$ is the dead time. For simplicity, both the open-loop gain $(K)$ and the time constant $(\tau)$ are considered to be unity and four different values of dead time $(L=0.05 \mathrm{~s}, 0.1 \mathrm{~s}, 0.2 \mathrm{~s}, 0.3 \mathrm{~s})$ are considered during simulation study. Dead time $L=0.05 \mathrm{~s}$ is considered as nominal dead time and then it is varied as $L=0.1 \mathrm{~s}, 0.2 \mathrm{~s}, 0.3 \mathrm{~s}$ for evaluating the robustness of the 
Fig. 6 Responses and control actions for Model I using 25 rules during set point response and with load variation for a $L=0.05 \mathrm{~s}, \mathbf{b} L=0.3 \mathrm{~s}$
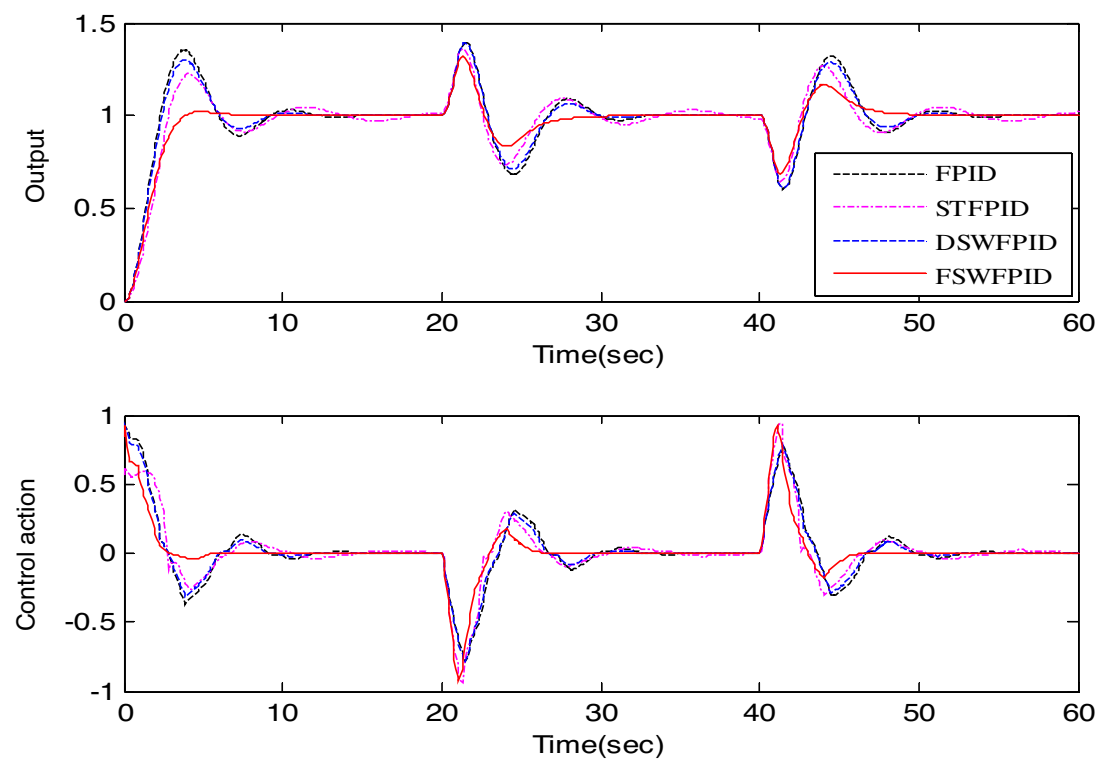

(a)
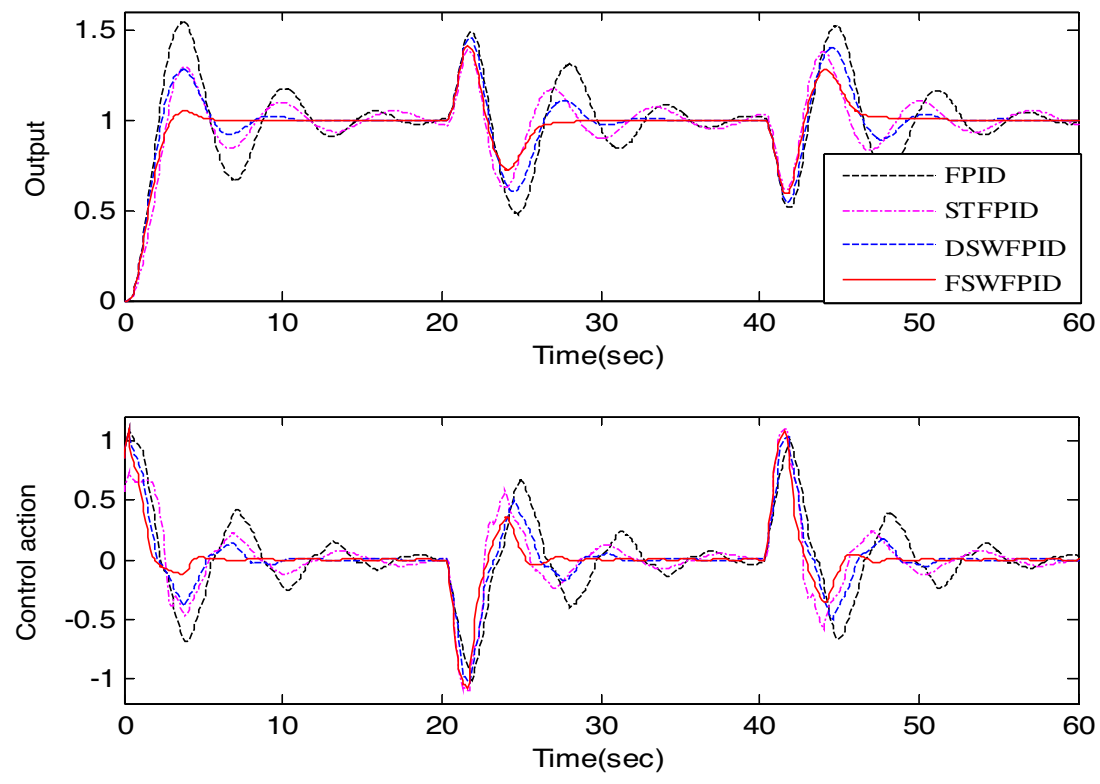

(b) tuned controller (for the nominal model). Closed-loop performance of the proposed FSWFPID is analysed in comparison with conventional fuzzy PID (FPID), self-tuning fuzzy PID (STFPID) [24] and dynamic set point weighting-based fuzzy PID (DSWFPID) [21] controllers. In all cases, control rule bases of the fuzzy controllers are considered to be identical, consisting of 49 and 25 rules. Figure $5 a$ and $b$ depict the closed-loop responses during set point tracking and load recovery phases with dead time $L=0.05 \mathrm{~s}$ and $L=0.3 \mathrm{~s}$, respectively, involving 49 control rules. Similarly,
Fig. $6 \mathrm{a}$ and $\mathrm{b}$ represent the closed-loop responses for $L=$ $0.05 \mathrm{~s}$ and $L=0.3 \mathrm{~s}$ with 25 control rules. Tables 4 and 5 contain the performance indices in terms of percentage overshoot (\%OS), rise time $\left(t_{r}\right)$, settling time $\left(t_{s}\right)$, integral absolute error (IAE), integral time absolute error (ITAE) and total variantion in control action (TV) during closed-loop operation with 49 and 25 control rules, respectively. From the responses (Fig. 5a, b) and the listed performance indices (Table 4) it is found that overshoot has been entirely eliminated in case of our proposed FSWFPID with 49 
Table 4 Performance analysis for Model I

\begin{tabular}{|c|c|c|c|c|c|c|c|c|c|}
\hline Model & Rule & $L(s)$ & Controller & $\% \mathrm{OS}$ & $t_{r}(s)$ & $t_{s}(s)$ & IAE & ITAE & TV \\
\hline \multirow[t]{16}{*}{ I } & 49 & 0.05 & FPID & 30.3 & 2.2 & 20.0 & 4.56 & 86.24 & 0.74 \\
\hline & & & STFPID & 17.9 & 2.6 & 20.0 & 4.47 & 82.39 & 0.74 \\
\hline & & & DSWFPID & 23.7 & 2.3 & 11.0 & 4.10 & 75.59 & 0.70 \\
\hline & & & FSWFPID (proposed) & 0.0 & 3.8 & 8.7 & 3.05 & 45.94 & 0.56 \\
\hline & & 0.1 & FPID & 33.8 & 2.2 & 20.0 & 4.88 & 93.86 & 0.84 \\
\hline & & & STFPID & 18.4 & 2.6 & 20.0 & 4.60 & 85.41 & 0.84 \\
\hline & & & DSWFPID & 26.4 & 2.2 & 10.6 & 4.33 & 81.49 & 0.77 \\
\hline & & & FSWFPID (proposed) & 0.0 & 5.3 & 9.2 & 3.15 & 49.13 & 0.59 \\
\hline & & 0.2 & FPID & 42.8 & 2.1 & 16.9 & 5.87 & 116.2 & 1.08 \\
\hline & & & STFPID & 21.2 & 2.6 & 15.7 & 4.90 & 94.45 & 1.10 \\
\hline & & & DSWFPID & 26.3 & 2.3 & 11.7 & 4.35 & 81.24 & 0.87 \\
\hline & & & FSWFPID (proposed) & 0.0 & 5.8 & 9.7 & 3.30 & 53.3 & 0.65 \\
\hline & & 0.3 & FPID & 52.7 & 2.1 & 17.0 & 7.70 & 166.1 & 1.50 \\
\hline & & & STFPID & 27.0 & 2.6 & 17.2 & 6.10 & 128.9 & 1.60 \\
\hline & & & DSWFPID & 26.1 & 2.3 & 12.9 & 4.50 & 85.99 & 1.04 \\
\hline & & & FSWFPID (proposed) & 0.0 & 6.4 & 6.4 & 3.40 & 57.02 & 0.89 \\
\hline
\end{tabular}

\begin{tabular}{|c|c|c|c|c|c|c|c|c|c|}
\hline Model & Rule & $L(s)$ & Controller & $\% O S$ & $t_{r}(s)$ & $t_{s}(s)$ & IAE & ITAE & TV \\
\hline \multirow[t]{16}{*}{1} & \multirow[t]{16}{*}{25} & \multirow[t]{4}{*}{0.05} & FPID & 35.6 & 2.4 & 15.3 & 5.72 & 116.3 & 0.74 \\
\hline & & & STFPID & 22.5 & 2.9 & * & 5.63 & 113.8 & 0.78 \\
\hline & & & DSWFPID & 30.0 & 2.5 & 12.4 & 5.16 & 101.9 & 0.68 \\
\hline & & & FSWFPID (proposed) & 2.1 & 3.9 & 7.1 & 3.65 & 63.34 & 0.57 \\
\hline & & \multirow[t]{4}{*}{0.1} & FPID & 37.8 & 2.3 & 14.9 & 6.22 & 131.1 & 0.84 \\
\hline & & & STFPID & 23.0 & 2.9 & $*$ & 5.88 & 121.8 & 0.88 \\
\hline & & & DSWFPID & 31.9 & 2.4 & 15.0 & 5.52 & 112.7 & 0.76 \\
\hline & & & FSWFPID (proposed) & 2.1 & 3.8 & 6.8 & 3.73 & 67.03 & 0.59 \\
\hline & & \multirow[t]{4}{*}{0.2} & FPID & 45.5 & 2.3 & * & 7.53 & 166.1 & 1.10 \\
\hline & & & STFPID & 25.5 & 2.8 & * & 6.40 & 135.7 & 1.03 \\
\hline & & & DSWFPID & 30.4 & 2.4 & 14.3 & 5.62 & 116.7 & 0.85 \\
\hline & & & FSWFPID (proposed) & 3.5 & 3.4 & 7.0 & 3.92 & 73.85 & 0.68 \\
\hline & & \multirow[t]{4}{*}{0.3} & FPID & 54.5 & 2.2 & * & 10.11 & 241.1 & 1.50 \\
\hline & & & STFPID & 29.0 & 2.8 & $*$ & 7.11 & 157.2 & 1.24 \\
\hline & & & DSWFPID & 27.9 & 2.5 & 13.3 & 5.84 & 126.0 & 0.98 \\
\hline & & & FSWFPID (proposed) & 4.8 & 3.1 & 6.5 & 4.12 & 80.87 & 0.79 \\
\hline
\end{tabular}

${ }^{*}$ Not settled

Table 5 Performance analysis for Model I control rules. In addition, considerable performance enhancement has also been observed during load recovery phase compared to FPID, STFPID and DSWFPID. Here, it is to note that performance enhancement is obtained in case of our proposed FSWFPID with lesser control effort as depicted by the smaller values of TV in comparison with other fuzzy PID controllers. Superior closed-loop performance is also reported by the proposed FSWFPID with 25 control rules as depicted in Fig. $6 \mathrm{a}$ and $\mathrm{b}$ for $L=0.05 \mathrm{~s}$ and $L=0.3 \mathrm{~s}$, and related performance indices are listed in Table 5. Moreover, to substantiate the supremacy of the proposed controller, its performance (Eq. (12)) is compared with fuzzy sliding mode controller and the related responses and control actions are depicted in Fig. $7 a$ and $\mathrm{b}$ for $L=0.05 \mathrm{~s}$ and $L=0.3 \mathrm{~s}$ with 49 rules. Similarly, closedloop responses with 25 rules are depicted in Fig. $8 \mathrm{a}$ and $\mathrm{b}$ and all the related performance indices are listed in Table 6. The variation of weighting factor for DSWFPID and 
Fig. 7 Comparison among responses and control actions with FSMC for Model I using 49 rules during set point response and with load variation for $\mathbf{a}$ $L=0.05 \mathrm{~s}, \mathbf{b} L=0.3 \mathrm{~s}$
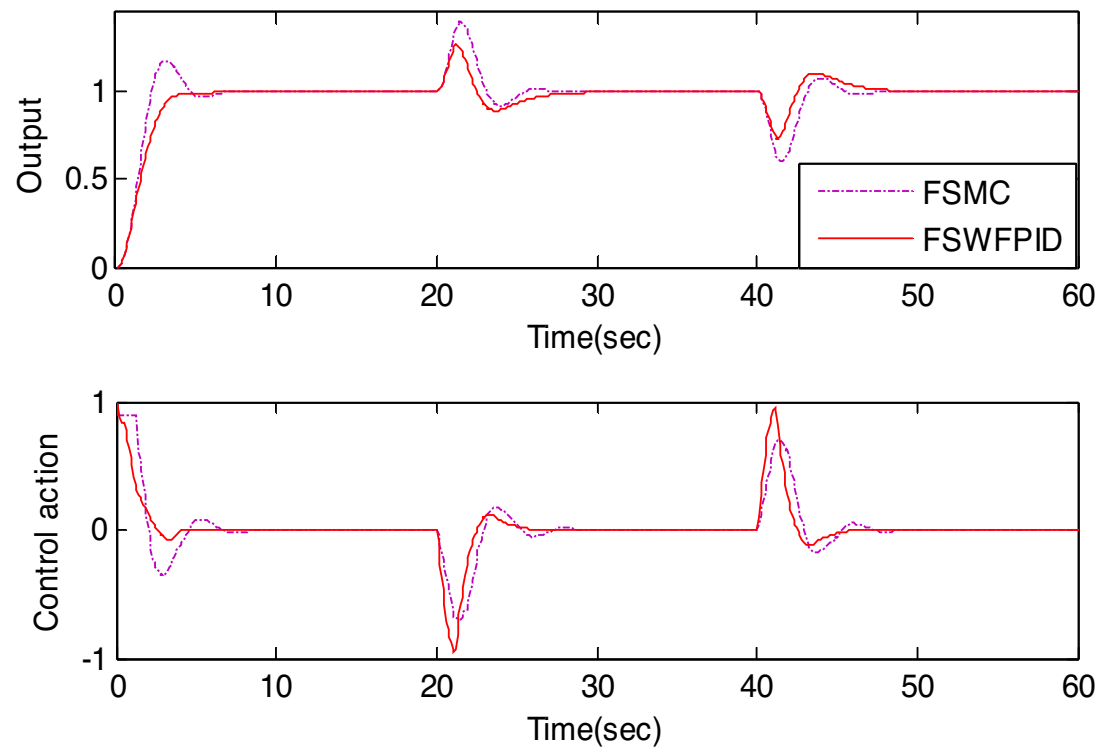

(a)
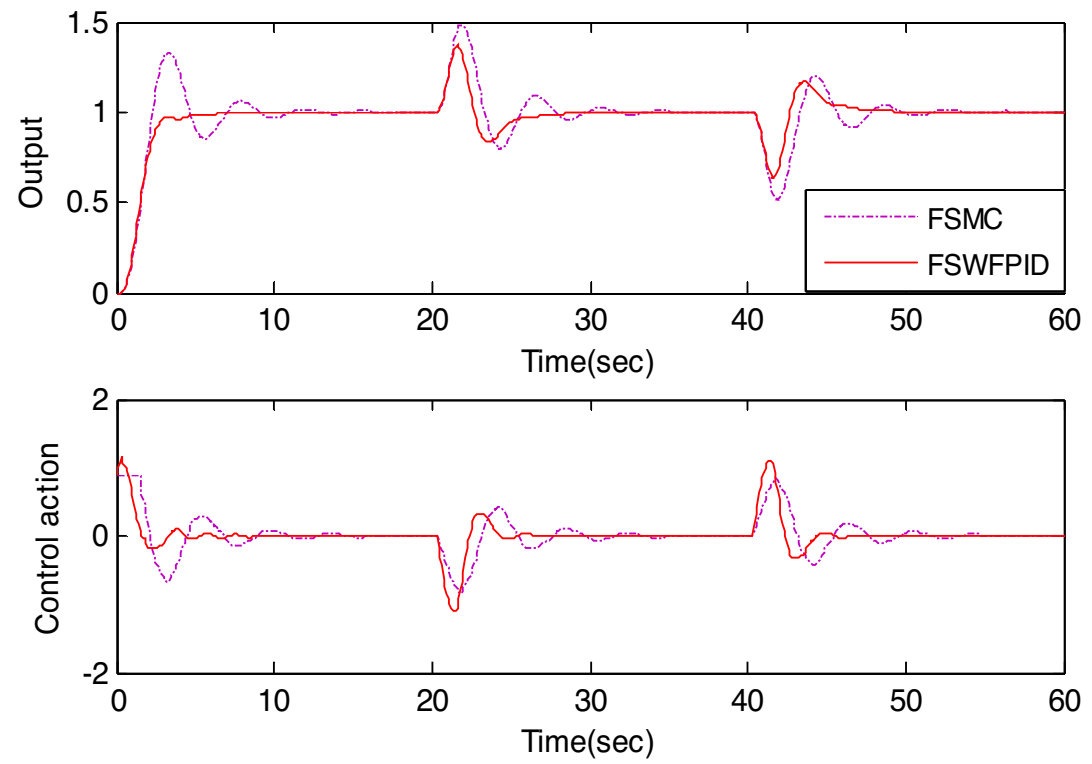

(b)
FSWFPID with 49 and 25 rules for Model I with dead time $L=0.3 \mathrm{~s}$ are shown in Fig. $9 \mathrm{a}$ and $\mathrm{b}$, respectively. Based on the responses and performance indices, it is found that the proposed FSWFPID offers improved set point tracking and good load regulation compared to FPID, STFPID, DSWFPID and FSMC even in the presence of parametric uncertainties.

\subsubsection{Model II: Second-order plus dead time (SOPDT) process $[12,13,18,24]$}

A typical SOPDT process model is given by Eq. (16)
$G_{2}(s)=\frac{k e^{-L s}}{(s+1)^{2}}$.

During simulation study four different values of dead time (i.e. $L=0.05 \mathrm{~s}, 0.1 \mathrm{~s}, 0.2 \mathrm{~s}, 0.3 \mathrm{~s}$ ) are considered where $L=0.1 \mathrm{~s}$ is considered as nominal dead time and rest three perturbed values of dead times are considered for evaluating the robustness of the controller. Closed-loop responses along with their respective control actions with 49 rules are evaluated for $L=0.1 \mathrm{~s}$ and $L=0.3 \mathrm{~s}$ as shown in Fig. 10a and b, respectively. Related performance indices are listed in Table 7. Likewise, the responses for $L=0.1 \mathrm{~s}$ 
Fig. 8 Comparison among responses and control actions for Model I with FSMC using 25 rules during set point response and with load variation for $\mathbf{a}$ $L=0.05 \mathrm{~s}, \mathbf{b} L=0.3 \mathrm{~s}$
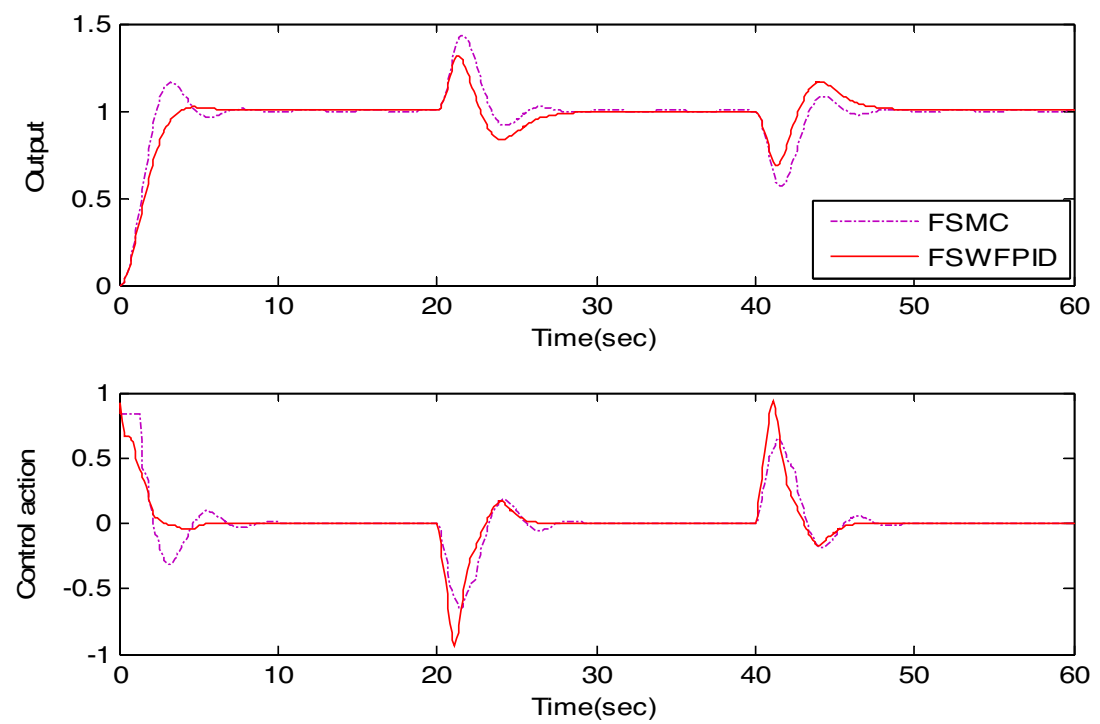

(a)
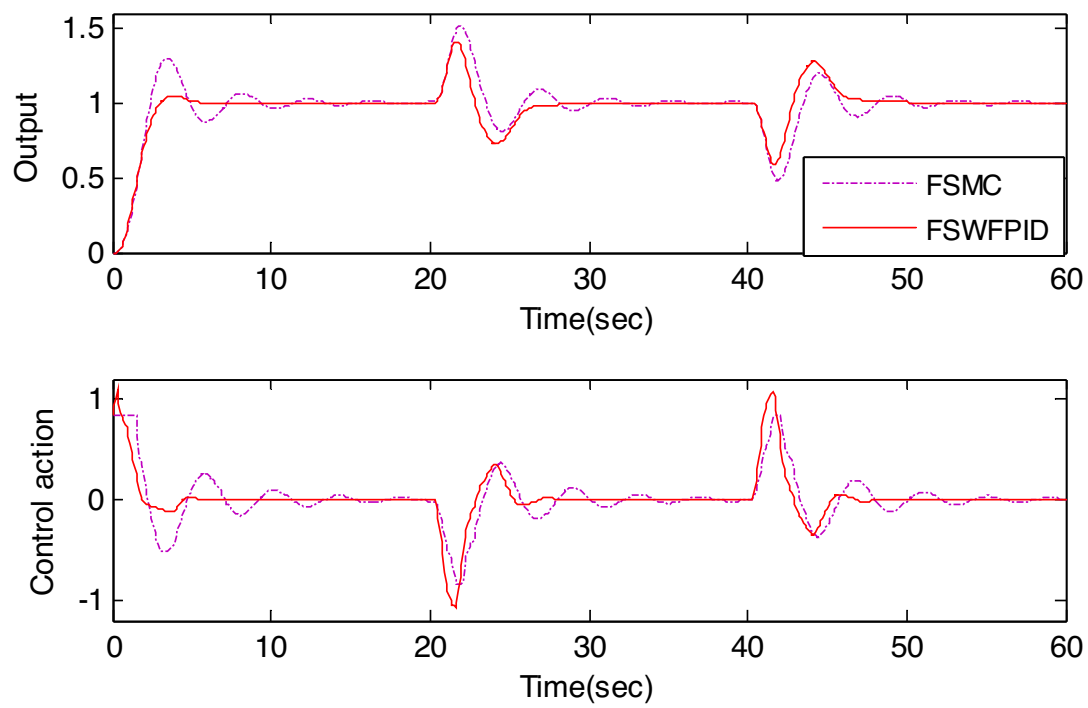

(b)
Table 6 Performance analysis for Model I

\begin{tabular}{|c|c|c|c|c|c|c|c|c|c|}
\hline Model & Rule & $L(s)$ & Controller & $\% O S$ & $t_{r}(s)$ & $t_{s}(s)$ & IAE & ITAE & TV \\
\hline \multirow[t]{8}{*}{ I } & 49 & 0.05 & FSMC & 17.3 & 2.3 & 8.9 & 3.32 & 54.48 & 0.57 \\
\hline & & & FSWFPID (proposed) & 0.0 & 3.8 & 8.7 & 3.05 & 45.94 & 0.56 \\
\hline & & 0.3 & FSMC & 32.9 & 2.3 & 14.7 & 5.09 & 95.54 & 1.04 \\
\hline & & & FSWFPID (proposed) & 0.0 & 6.4 & 6.4 & 3.40 & 57.02 & 0.89 \\
\hline & 25 & 0.05 & FSMC & 16.1 & 2.4 & 11.5 & 3.65 & 64.0 & 0.57 \\
\hline & & & FSWFPID (proposed) & 2.1 & 3.9 & 7.1 & 3.65 & 63.34 & 0.57 \\
\hline & & 0.3 & FSMC & 29.8 & 1.05 & 19.0 & 5.47 & 108.0 & 1.03 \\
\hline & & & FSWFPID (proposed) & 4.8 & 3.1 & 6.5 & 4.12 & 80.87 & 0.79 \\
\hline
\end{tabular}


Fig. 9 Variation of weighting factor corresponding to closed-loop responses provided by DSWFPID and FSWFPID for Model I with a 49 rules and $\mathbf{b} 25$ rules
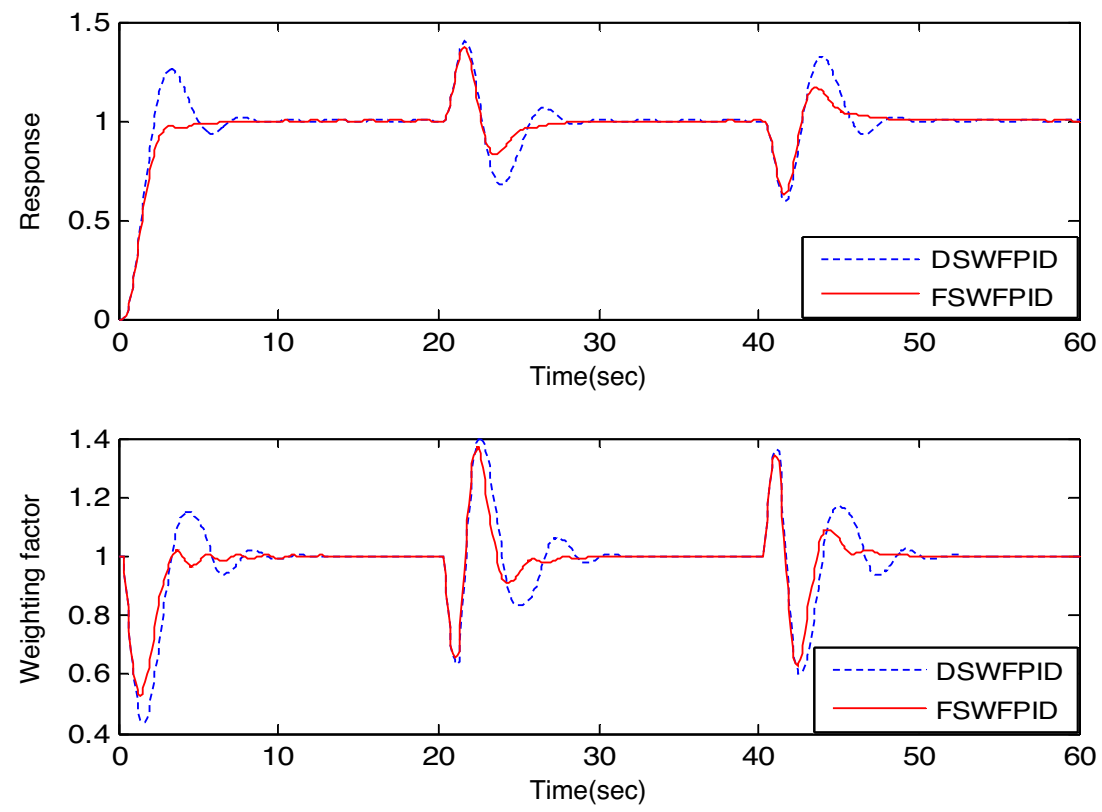

(a)
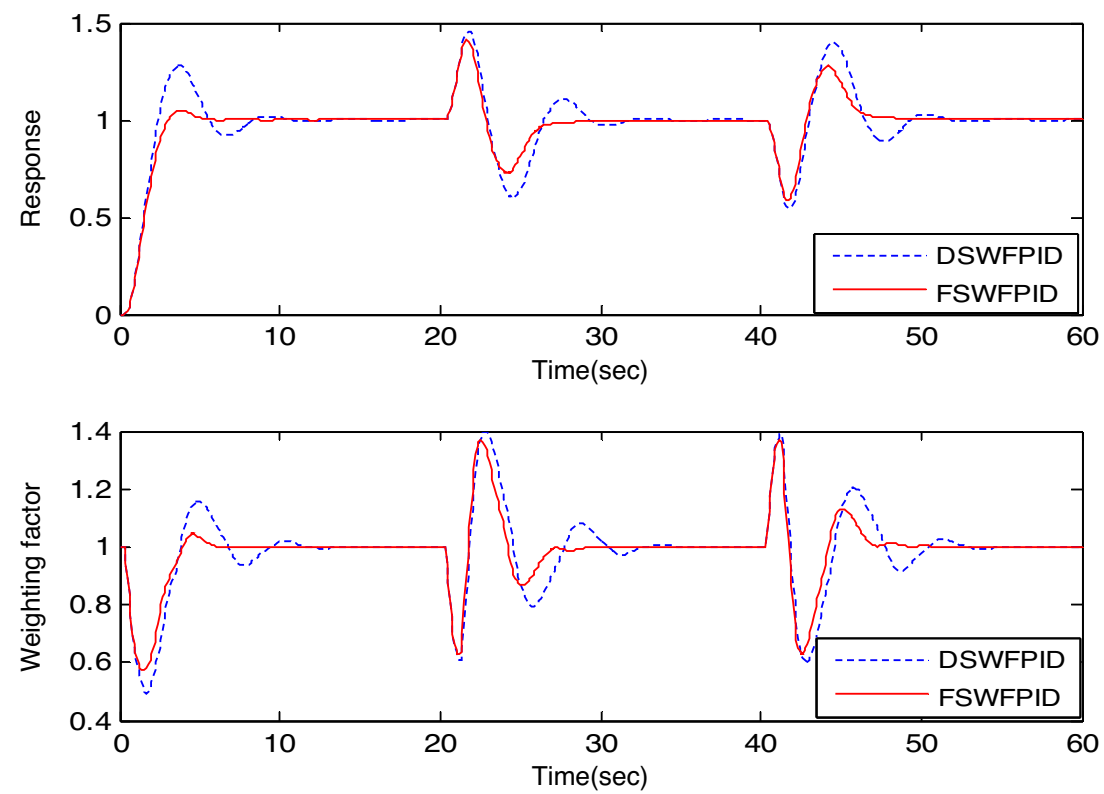

(b) and $L=0.3 \mathrm{~s}$ with 25 rules are depicted in Fig. $11 \mathrm{a}$ and $\mathrm{b}$, and the corresponding performance indices are shown in Table 8. From the listed values of performance indices, it is quite evident that the proposed FSWFPID is capable of restricting the initial overshoot and the load recovery is relatively faster than FPID, STFPID and DSWFPID with superior control effort.

\subsubsection{Model III: Integrating fifth-order plus dead time process [32-34]}

$G_{3}(s)=\frac{K e^{-L s}}{s(\tau s+1)^{4}}$. 
Fig. 10 Responses and control actions for Model II using 49 rules during set point response and with load variation for $\mathbf{a}$ $L=0.1 \mathrm{~s}, \mathbf{b} L=0.3 \mathrm{~s}$
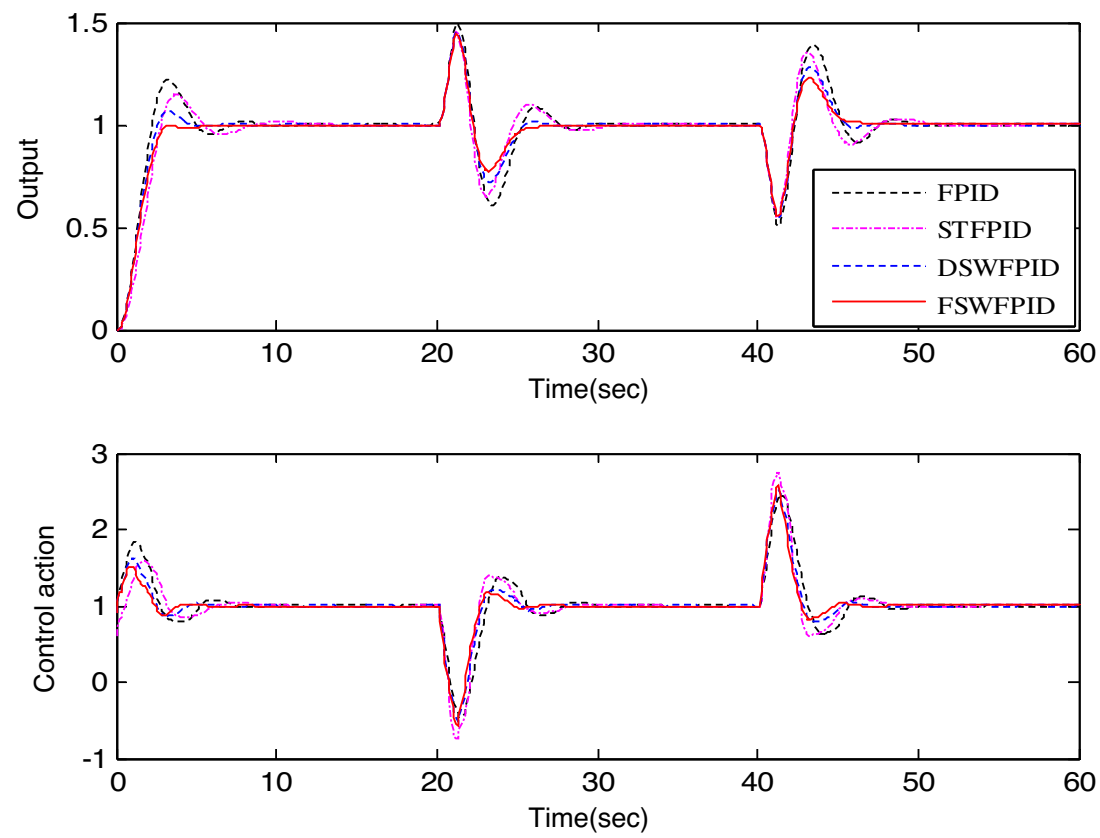

(a)
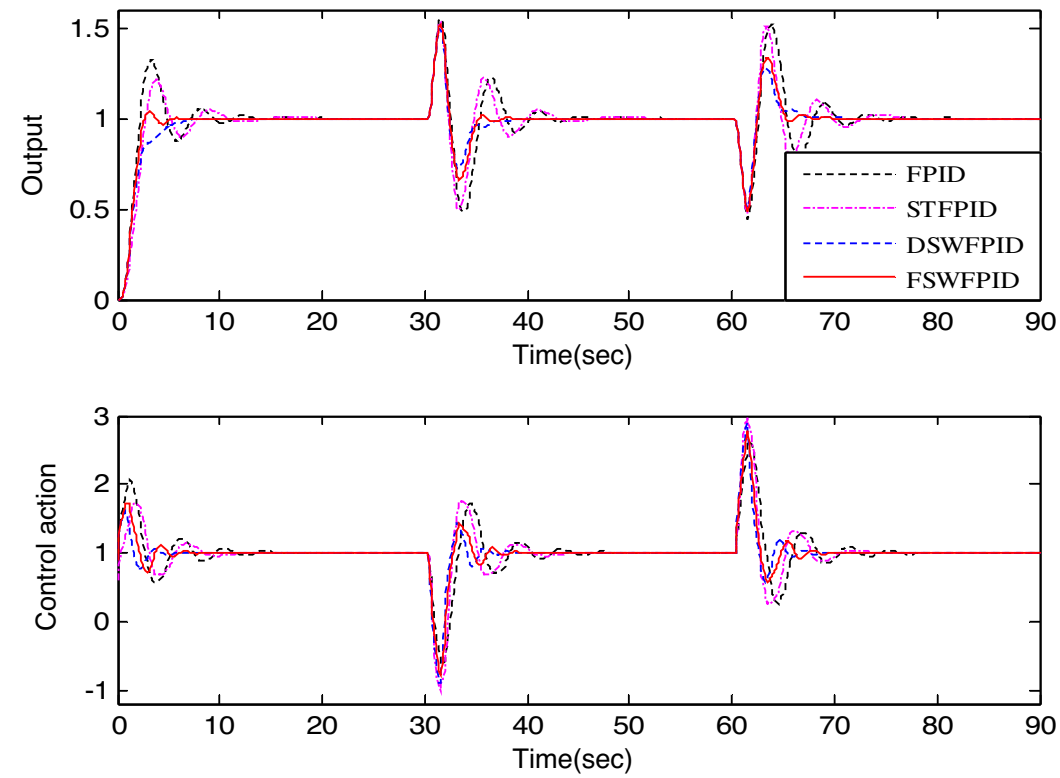

(b)
Here, we consider a fifth-order integrating plus dead time process model with unity time constant $(\tau)$ and dead time $L=0.3 \mathrm{~s}, 0.5 \mathrm{~s}$ and $0.7 \mathrm{~s}$ where $L=0.5 \mathrm{~s}$ is chosen as the nominal dead time. Closed-loop performance of the proposed FSWFPID controller is analysed in comparison with the other reported controllers (FPID and STFPID) and in all cases the input and output scaling factors of the fuzzy controllers are considered to be identical with similar control rule bases consisting of 49 and 25 rules. Figure 12a and b depicts the closed-loop responses with 49 control rules for $L=0.3 \mathrm{~s}$ and $0.5 \mathrm{~s}$. Similarly, Fig. 13a and $\mathrm{b}$ shows the responses with 25 rules for $L=0.5 \mathrm{~s}$ and $0.7 \mathrm{~s}$. Performance indices for the proposed controller along with FPID and STFPID controller are listed in Tables 9 and 10 for 49 rules and 25 rules, respectively. Closed-loop responses with the proposed FSWFPID and a well-known FSMC technique for 
Table 7 Performance analysis for Model II

\begin{tabular}{|c|c|c|c|c|c|c|c|c|c|}
\hline Model & Rule & $L(s)$ & Controller & $\% \mathrm{OS}$ & $t_{r}(s)$ & $t_{s}(s)$ & IAE & ITAE & TV \\
\hline \multirow[t]{16}{*}{ II } & \multirow[t]{16}{*}{49} & \multirow[t]{4}{*}{0.05} & FPID & 18.8 & 2.3 & 9.5 & 4.42 & 90.60 & 0.95 \\
\hline & & & STFPID & 13.0 & 2.9 & 9.2 & 4.45 & 84.50 & 1.05 \\
\hline & & & DSWFPID & 4.9 & 2.7 & 6.9 & 3.53 & 66.42 & 0.82 \\
\hline & & & FSWFPID (proposed) & 0.0 & 5.2 & 5.2 & 3.40 & 60.48 & 0.79 \\
\hline & & \multirow[t]{4}{*}{0.1} & FPID & 21.6 & 2.3 & 11.5 & 4.76 & 99.69 & 1.10 \\
\hline & & & STFPID & 14.7 & 2.9 & 13.4 & 4.70 & 90.95 & 1.14 \\
\hline & & & DSWFPID & 6.3 & 2.7 & 6.6 & 3.68 & 70.36 & 0.89 \\
\hline & & & FSWFPID (proposed) & 0.0 & 3.2 & 5.9 & 3.50 & 63.18 & 0.86 \\
\hline & & \multirow[t]{4}{*}{0.2} & FPID & 26.9 & 2.3 & 11.3 & 5.54 & 121.0 & 1.29 \\
\hline & & & STFPID & 18.0 & 2.8 & 11.9 & 5.36 & 109.8 & 1.35 \\
\hline & & & DSWFPID & 0.0 & 5.6 & 8.3 & 3.60 & 63.80 & 1.05 \\
\hline & & & FSWFPID (proposed) & 1.0 & 3.0 & 5.4 & 3.60 & 61.90 & 1.00 \\
\hline & & \multirow[t]{4}{*}{0.3} & FPID & 32.7 & 2.3 & 17.2 & 6.80 & 223.3 & 1.63 \\
\hline & & & STFPID & 21.9 & 2.8 & 14.9 & 6.40 & 202.8 & 1.60 \\
\hline & & & DSWFPID & 0.0 & 7.4 & 7.4 & 4.20 & 107.3 & 1.28 \\
\hline & & & FSWFPID (proposed) & 3.5 & 2.7 & 6.8 & 4.00 & 104.3 & 1.20 \\
\hline
\end{tabular}

$L=0.3 \mathrm{~s}$ and $0.5 \mathrm{~s}$ with identical 49 rules are depicted in Fig. 14a and b. Similarly, responses with 25 rules are shown in Fig. 15a and b. Performance indices for the proposed controller along with FSMC are listed in Table 11. From the closed-loop responses and performance indices, it is found that the performance of the proposed FSWFPID controller is quite satisfactory with minimum overshoot and smaller IAE and ITAE values compared to FPID and STFPID. Here, it is to mention that the tuning parameters are not easy to calculate for DSWFPID with this fifth-order model.

\subsubsection{Model IV: Second-order nonlinear process model [24]}

$\frac{\mathrm{d}^{2} \mathrm{y}}{\mathrm{dt}^{2}}+0.3 y \frac{\mathrm{dy}}{\mathrm{dt}}=u(t-L)$.

Performance of the reported controllers along with the proposed FSWFPID are also verified for a secondorder nonlinear process as given by Eq. (18) for dead time $L=0.2 \mathrm{~s}$. Parametric variations are considered for evaluating the performances robustness with $L=0.05 \mathrm{~s}, 0.1 \mathrm{~s}$ and $0.3 \mathrm{~s}$ with the same controller settings for the nominal model. Closed-loop responses with 49 rules for $L=0.2 \mathrm{~s}$ and $0.3 \mathrm{~s}$ are shown in Fig. 16a and $b$, respectively, for the conventional FPID, STFPID and DSWFPID controllers. Corresponding performance indices are depicted in Table 12. Similar set of responses with 25 rules are shown in Fig. 17a and $\mathrm{b}$ and the related performance indices are listed in Table 13. Performance comparison is also made with FSMC as shown in Fig. 18a and b using 49 rules with $L=0.1 \mathrm{~s}$ and $0.3 \mathrm{~s}$. Similarly, responses with 25 rules are depicted in Fig. 19a and b and the related performance indices are listed in Table 14. Here, it is note that FSWFPID results zero overshoot and considerable performance enhancement is observed (substantiated by smaller IAE and ITAE values) during load recovery phases compared to FPID, STFPID, DSWFPID and FSMC. Furthermore, total exerted control effort as given by TV value is also found to be smaller for FSWFPID.

\subsubsection{Model V: Third-order nonlinear process model}

$\frac{d^{3} y}{d t^{3}}+\frac{d^{2} y}{d t^{2}}+0.5 y \frac{d y}{d t}=u(t-L)$.

Performance of FSWFPID is also demonstrated for a third-order nonlinear process as given by Eq. (19) with dead time $L=0.1 \mathrm{~s}, 0.2 \mathrm{~s}$ and $0.3 \mathrm{~s}$. Dead time $L=0.2 \mathrm{~s}$ is chosen as the nominal dead time and consequently $\pm 50 \%$ perturbations are incorporated to justify the robustness of the proposed controller. Its responses along with their respective control actions for $L=0.2 \mathrm{~s}$ and $0.3 \mathrm{~s}$ with 49 are shown in Fig. 20a and b and with 25 rules are shown in Fig. 21a and b, respectively. Here, closed-loop responses for the proposed controller are compared with conventional FPID, STFPID and DSWFPID controllers. Closed-loop performance comparison is also made with FSMC for $L=0.2 \mathrm{~s}$ and $0.3 \mathrm{~s}$ and is shown in Figs. 22 
Fig. 11 Responses and control actions for Model II using 25 rules during set point response and with load variation for $\mathbf{a}$ $L=0.1 \mathrm{~s}, \mathbf{b} L=0.3 \mathrm{~s}$
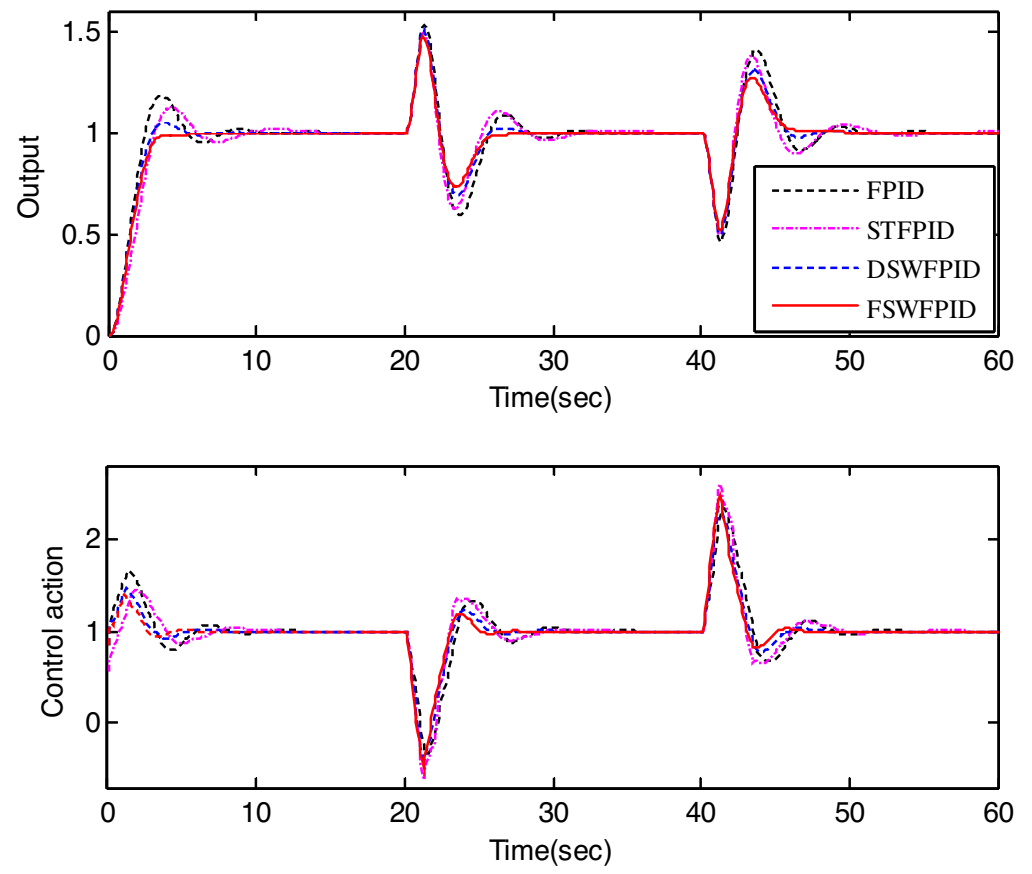

(a)
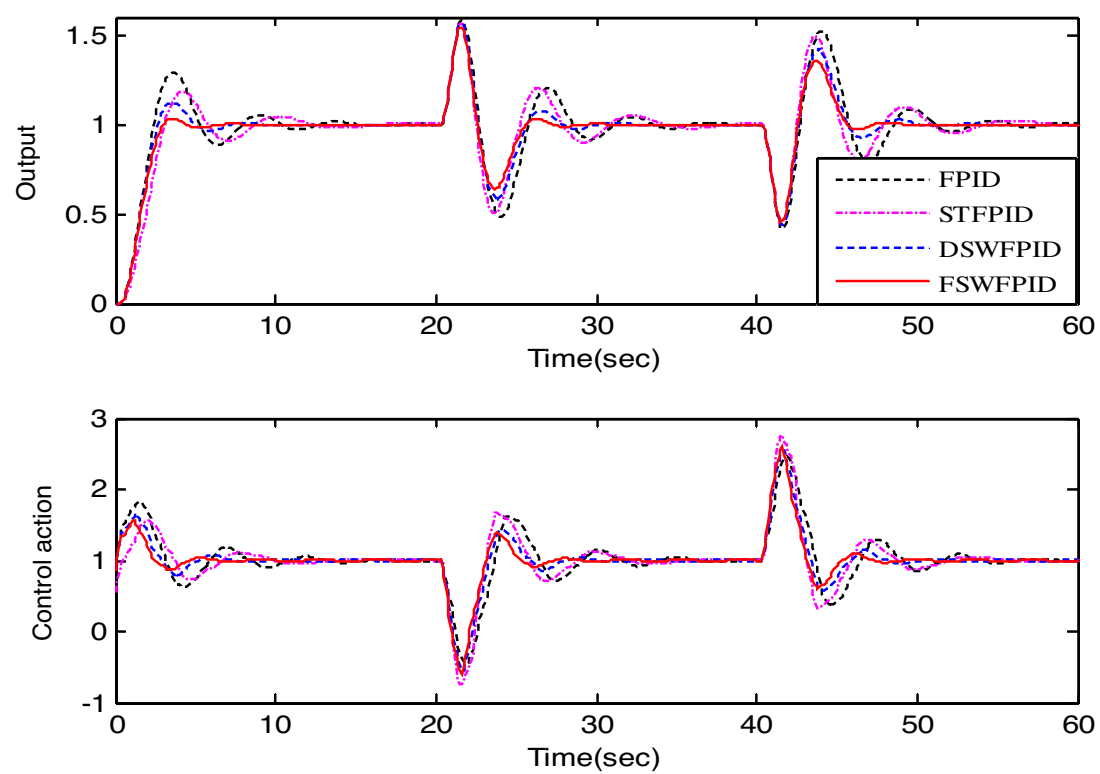

(b) 
Table 8 Performance analysis for Model II

\begin{tabular}{|c|c|c|c|c|c|c|c|c|c|}
\hline Model & Rule & $L(s)$ & Controller & $\% O S$ & $t_{r}(s)$ & $t_{s}(s)$ & IAE & ITAE & TV \\
\hline \multirow[t]{16}{*}{ II } & \multirow[t]{16}{*}{25} & \multirow[t]{4}{*}{0.05} & FPID & 16.0 & 2.6 & 13.0 & 4.94 & 105.6 & 0.89 \\
\hline & & & STFPID & 11.5 & 3.2 & 10.1 & 5.04 & 100.4 & 0.96 \\
\hline & & & DSWFPID & 4.0 & 3.2 & 9.6 & 4.02 & 78.28 & 0.77 \\
\hline & & & FSWFPID (proposed) & 0.0 & 3.8 & 5.5 & 3.90 & 72.24 & 0.75 \\
\hline & & \multirow[t]{4}{*}{0.1} & FPID & 18.4 & 2.5 & 12.8 & 5.32 & 116.2 & 0.97 \\
\hline & & & STFPID & 12.7 & 3.2 & 14.5 & 5.36 & 109.8 & 1.05 \\
\hline & & & DSWFPID & 4.7 & 3.0 & 7.9 & 4.20 & 83.68 & 0.82 \\
\hline & & & FSWFPID (proposed) & 0.0 & 3.6 & 8.0 & 3.98 & 75.53 & 0.81 \\
\hline & & \multirow[t]{4}{*}{0.2} & FPID & 23.9 & 2.5 & 12.7 & 6.10 & 137.2 & 1.15 \\
\hline & & & STFPID & 14.5 & 3.2 & 13.1 & 5.98 & 128.2 & 1.19 \\
\hline & & & DSWFPID & 8.3 & 2.8 & 9.6 & 4.58 & 94.70 & 0.95 \\
\hline & & & FSWFPID (proposed) & 0.0 & 3.4 & 7.1 & 4.12 & 80.46 & 0.88 \\
\hline & & \multirow[t]{4}{*}{0.3} & FPID & 29.4 & 2.5 & 20.0 & 7.30 & 171.7 & 1.43 \\
\hline & & & STFPID & 18.3 & 3.1 & 17.6 & 6.90 & 158.7 & 1.45 \\
\hline & & & DSWFPID & 12.2 & 2.7 & 11.6 & 5.15 & 110.8 & 1.11 \\
\hline & & & FSWFPID (proposed) & 3.2 & 3.1 & 6.7 & 4.44 & 90.24 & 1.03 \\
\hline
\end{tabular}

and 23, respectively, with 49 rules and 25 rules. Related performance indices are listed in Table 15 for 49 rules and Table 16 for 25 rules. Superiority of FSWFPID is also observed for this third-order nonlinear model in terms of smaller overshoot and faster settling in comparison with FPID, STFPID, DSWFPID and FSMC. Acceptable robustness of the proposed FSWFPID is also substantiated under parametric uncertainities of the nonlinear process model.

\subsection{Real-time experimentation}

In addition to the simulation study, performance of FSWFPID along with FPID, STFPID and DSWFPID is evaluated on a PC-based servo position control system QUBE-Servo 2 by Quanser [31]. It is a compact rotary servo unit with inbuilt DAQ to perform a range of servo control experiments. During experimentation, the QUBE-Servo 2 has been configured with the QFLEX 2 module which allows control by a computer via USB connection. An easily attachable inertia $\left(0.6 \times 10-6 \mathrm{~kg}-\mathrm{m}^{2}\right)$ disc is driven by a direct drive $18 \mathrm{~V}$ brushed DC motor. Rotary encoders (2048 lines/revolution) are used to measure the angular position of the disc and the angular velocity of the motor can also be measured.

Connection between the different system components on the QUBE-Servo 2 is illustrated in Fig. 24a and the snapshot of the experimental setup is depicted in Fig. 24b. Motor and encoders are connected to the encoder input (EI) of the data acquisition (DAQ) block. The analog output (AO) channel is connected to the power amplifier which drives the DC motor. The DAQ analog input (AI) channel is connected to the PWM amplifier. The DAQ can be interfaced to the PC via USB link in the QFLEX 2 USB. All the reported fuzzy controllers along with FSWFPID are designed with the help of MATLAB-Simulink for their performance evaluation on QUBE-Servo 2. For position control, open-loop transfer function of the motor is given by

$G_{\theta}(s)=\frac{26.5 \mathrm{e}^{-0.01 s}}{s(0.155 s+1)}$

Responses and the related control actions of all the reported fuzzy controllers with 49 control rules during 
Fig. 12 Responses and control actions for Model III using 49 rules during set point response and with load variation for a $L=0.3 \mathrm{~s}, \mathbf{b} L=0.05 \mathrm{~s}$
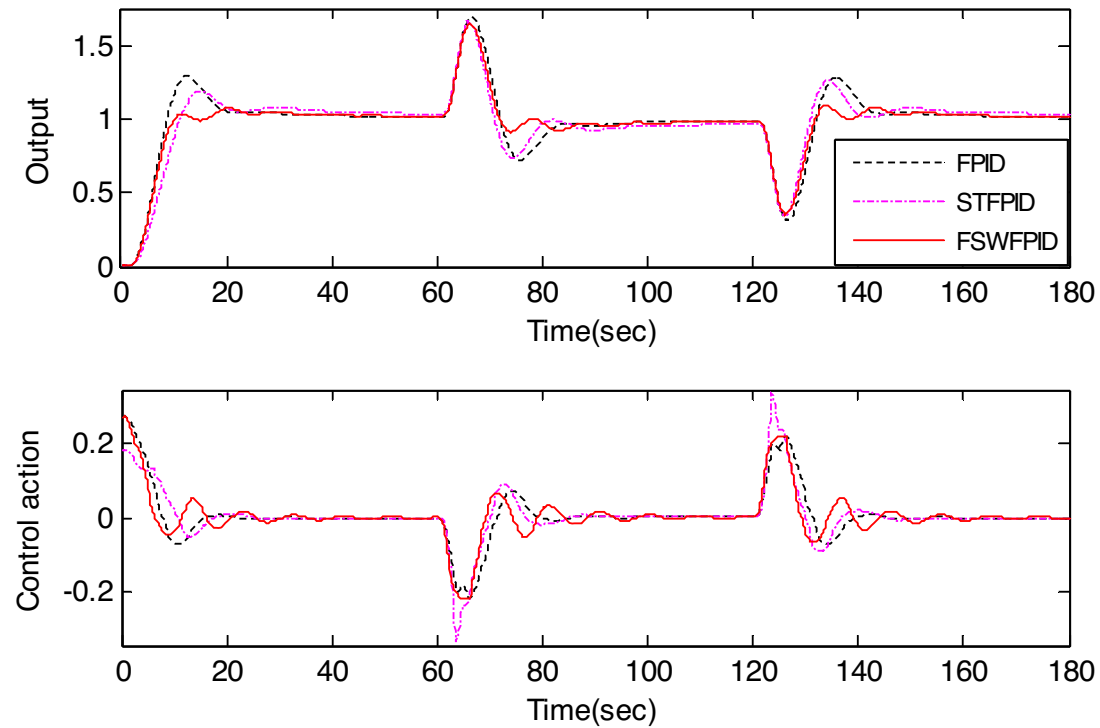

(a)
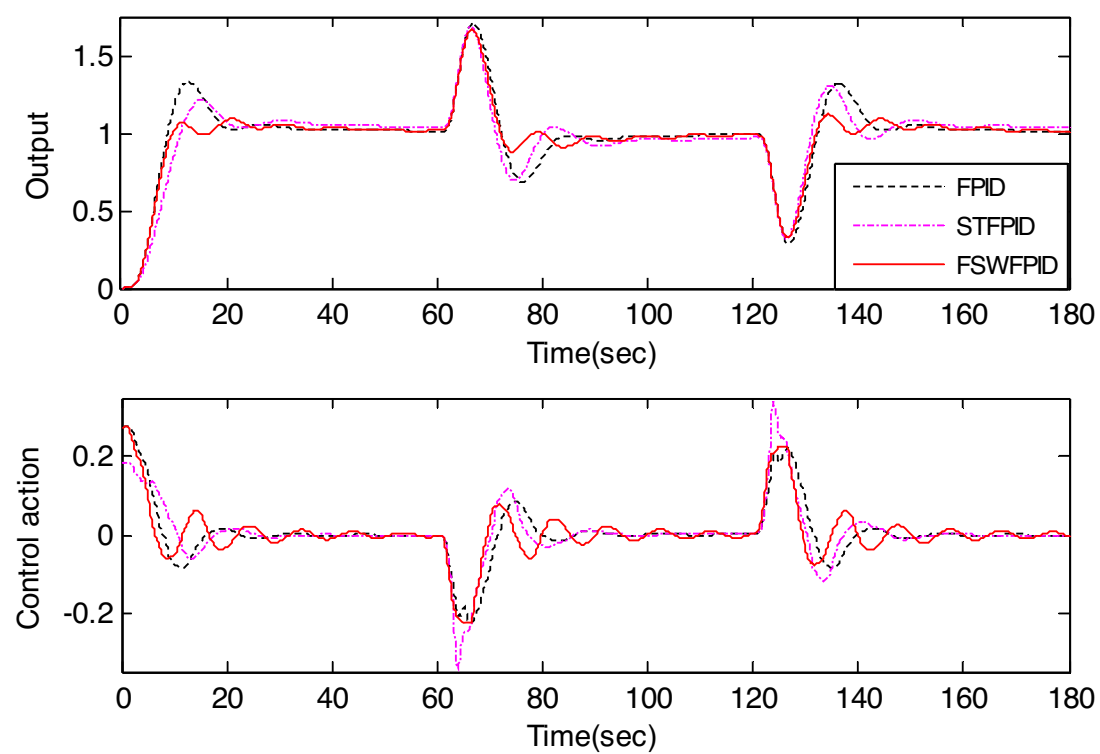

(b) 
Fig. 13 Responses and control actions for Model III using 25 rules during set point response and with load variation for $\mathbf{a}$ $L=0.05 \mathrm{~s}, \mathbf{b} L=0.7 \mathrm{~s}$
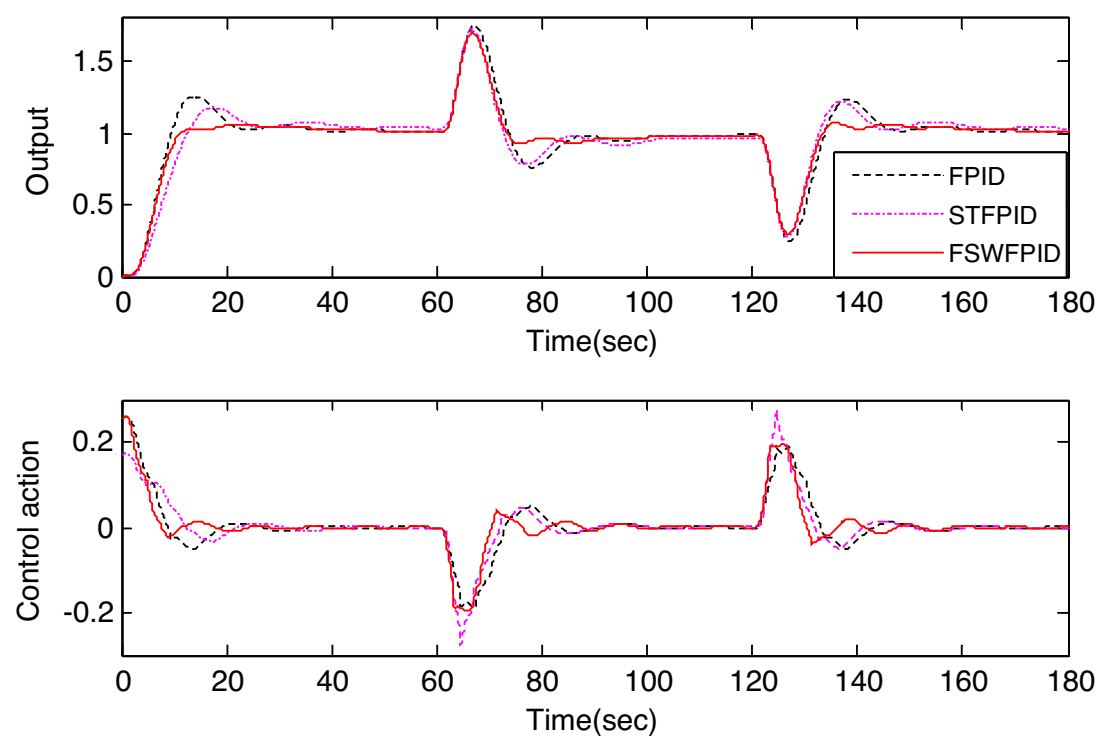

(a)
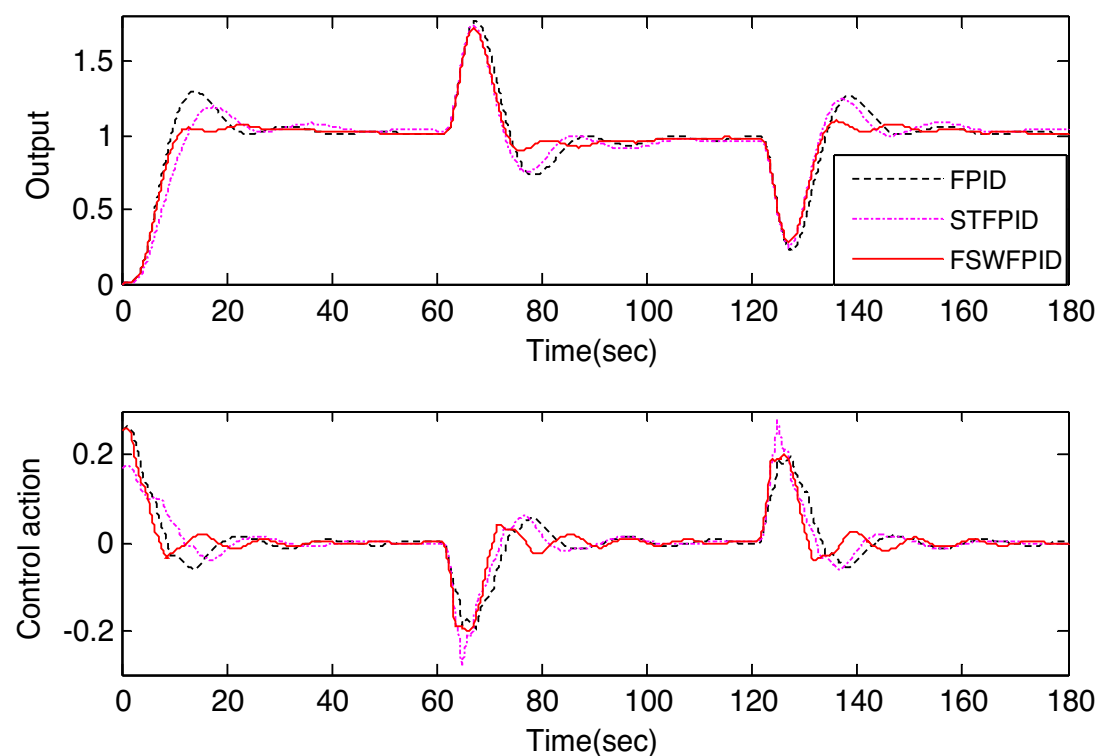

(b)
Table 9 Performance analysis for Model III

\begin{tabular}{|c|c|c|c|c|c|c|c|c|}
\hline Model & Rule & $L(s)$ & Controller & $\% O S$ & $t_{r}(s)$ & IAE & ITAE & TV \\
\hline \multirow[t]{9}{*}{ III } & 49 & 0.3 & FPID & 29.0 & 8.7 & 22.93 & 1531 & 0.25 \\
\hline & & & STFPID & 19.0 & 11.2 & 24.14 & 1590 & 0.30 \\
\hline & & & FSWFPID (proposed) & 3.2 & 10.2 & 18.25 & 1172 & 0.31 \\
\hline & & 0.5 & FPID & 33.1 & 8.8 & 23.82 & 1594 & 0.27 \\
\hline & & & STFPID & 21.4 & 11.3 & 24.91 & 1652 & 0.32 \\
\hline & & & FSWFPID (proposed) & 6.3 & 9.8 & 19.14 & 1238 & 0.35 \\
\hline & & 0.7 & FPID & 37.2 & 8.8 & 24.97 & 1685 & 0.32 \\
\hline & & & STFPID & 23.7 & 11.3 & 26.22 & 1784 & 0.36 \\
\hline & & & FSWFPID (proposed) & 9.9 & 9.5 & 20.45 & 1360 & 0.42 \\
\hline
\end{tabular}


Table 10 Performance analysis for Model III

\begin{tabular}{|c|c|c|c|c|c|c|c|c|}
\hline Model & Rule & $L(s)$ & Controller & $\% O S$ & $t_{r}(s)$ & IAE & ITAE & TV \\
\hline \multirow[t]{9}{*}{ III } & 25 & 0.3 & FPID & 22.2 & 9.6 & 23.86 & 1628 & 0.22 \\
\hline & & & STFPID & 16.5 & 12.6 & 25.88 & 1737 & 0.24 \\
\hline & & & FSWFPID (proposed) & 6.3 & 12.6 & 19.72 & 1279 & 0.22 \\
\hline & & 0.5 & FPID & 25.8 & 9.6 & 25.08 & 1722 & 0.24 \\
\hline & & & STFPID & 18.0 & 12.6 & 26.52 & 1786 & 0.25 \\
\hline & & & FSWFPID (proposed) & 2.8 & 11.4 & 20.47 & 1347 & 0.24 \\
\hline & & 0.7 & FPID & 29.6 & 9.5 & 26.41 & 1831 & 0.25 \\
\hline & & & STFPID & 19.5 & 12.5 & 27.03 & 1826 & 0.26 \\
\hline & & & FSWFPID (proposed) & 5.2 & 10.8 & 21.35 & 1425 & 0.26 \\
\hline
\end{tabular}

Fig. 14 Comparison among responses and control actions for Model III with FSMC using 49 rules during set point response and with load variation for $\mathbf{a} L=0.3 \mathrm{~s}, \mathbf{b} L=0.05 \mathrm{~s}$
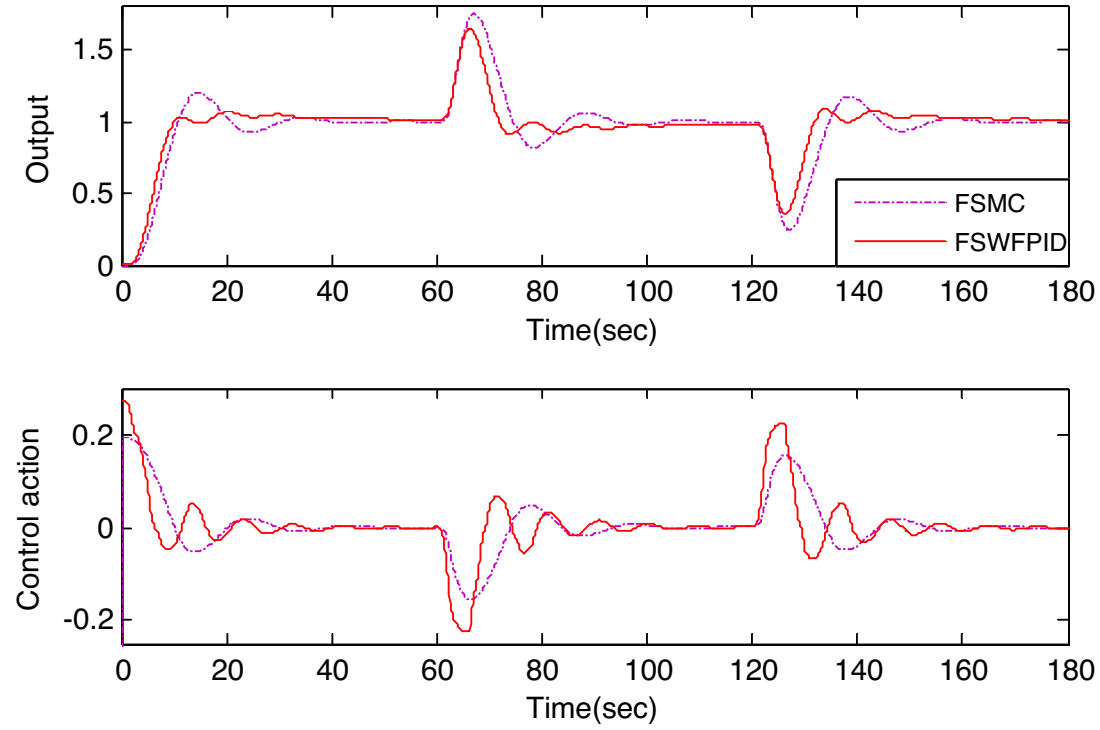

(a)
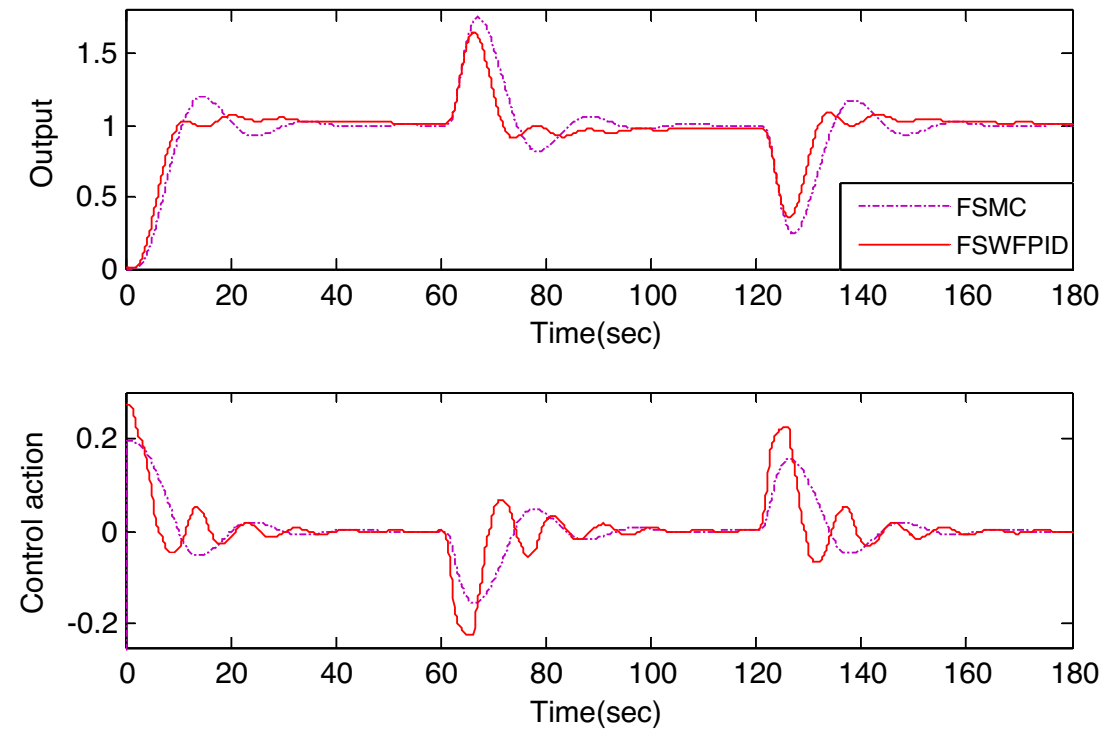

(b) 
Fig. 15 Comparison among responses and control actions for Model III with FSMC using 25 rules during set point response and with load variation for $\mathbf{a} L=0.3 \mathrm{~s}, \mathbf{b} L=0.05 \mathrm{~s}$
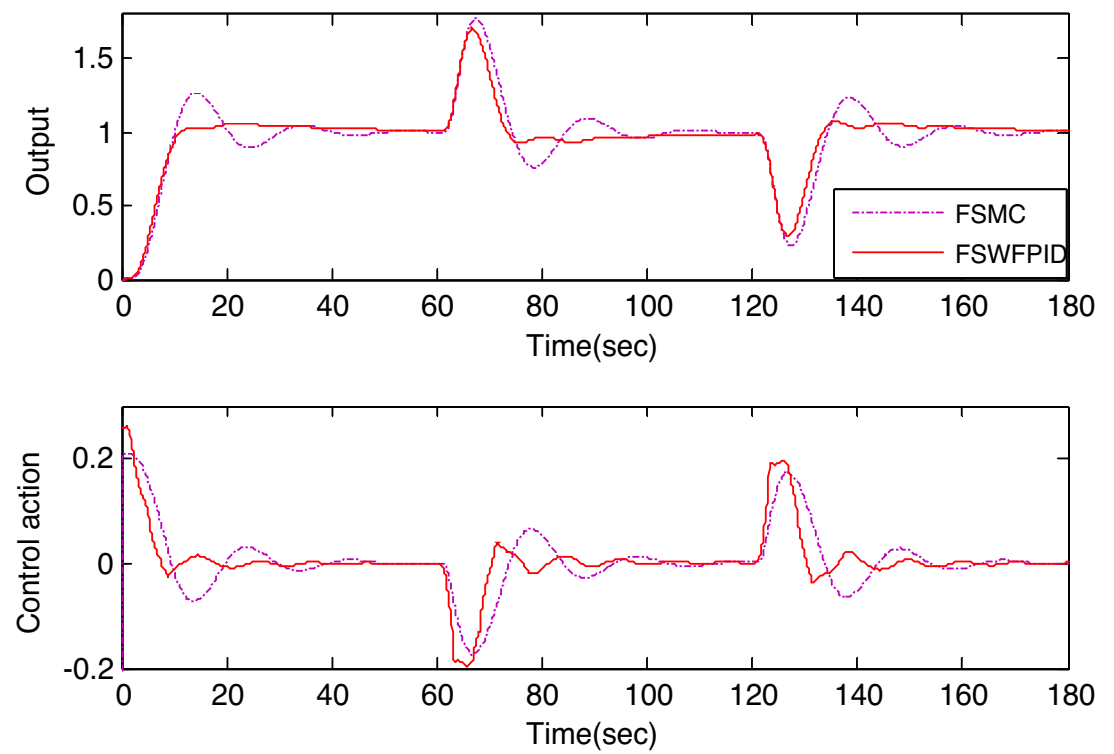

(a)
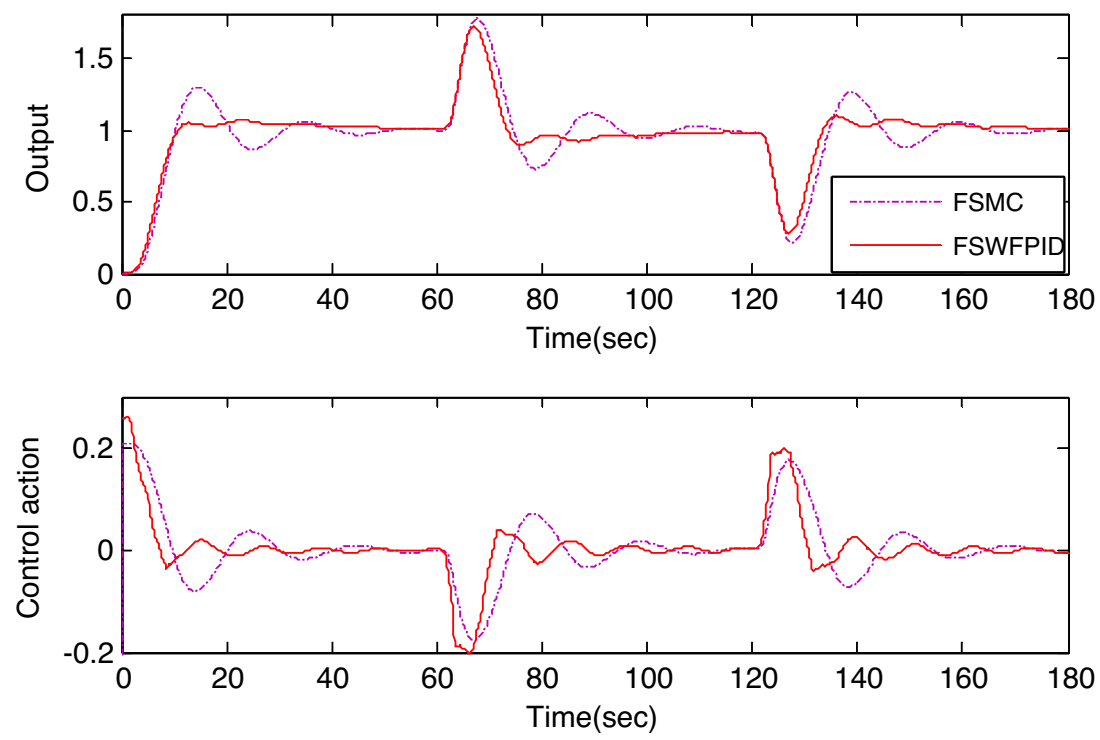

(b)
Table 11 Performance analysis for Model III

\begin{tabular}{|c|c|c|c|c|c|c|c|c|}
\hline Model & Rule & $L(s)$ & Controller & $\% \mathrm{OS}$ & $t_{r}(s)$ & IAE & ITAE & TV \\
\hline \multirow[t]{12}{*}{ III } & \multirow[t]{6}{*}{49} & \multirow[t]{2}{*}{0.3} & FSMC & 20.2 & 10.9 & 23.61 & 1546 & 0.35 \\
\hline & & & FSWFPID (proposed) & 3.2 & 10.2 & 18.25 & 1172 & 0.31 \\
\hline & & \multirow[t]{2}{*}{0.5} & FSMC & 23.0 & 10.8 & 25.18 & 1682 & 0.36 \\
\hline & & & FSWFPID (proposed) & 6.3 & 9.8 & 19.14 & 1238 & 0.35 \\
\hline & & \multirow[t]{2}{*}{0.7} & FSMC & 25.9 & 11.0 & 27.15 & 1841 & 0.37 \\
\hline & & & FSWFPID (proposed) & 9.9 & 9.5 & 20.45 & 1360 & 0.42 \\
\hline & \multirow[t]{6}{*}{25} & \multirow[t]{2}{*}{0.3} & FSMC & 24.1 & 10.2 & 24.1 & 1603 & 0.34 \\
\hline & & & FSWFPID (proposed) & 6.3 & 12.6 & 19.72 & 1279 & 0.22 \\
\hline & & \multirow[t]{2}{*}{0.5} & FSMC & 27.2 & 10.2 & 25.97 & 1762 & 0.35 \\
\hline & & & FSWFPID (proposed) & 2.8 & 11.4 & 20.47 & 1347 & 0.24 \\
\hline & & \multirow[t]{2}{*}{0.7} & FSMC & 30.5 & 10.3 & 28.22 & 1947 & 0.37 \\
\hline & & & FSWFPID (proposed) & 5.2 & 10.8 & 21.35 & 1425 & 0.26 \\
\hline
\end{tabular}


Fig. 16 Responses and control actions for Model IV using 49 rules during set point response and with load variation for $\mathbf{a}$ $L=0.2 \mathrm{~s}, \mathbf{b} L=0.3 \mathrm{~s}$
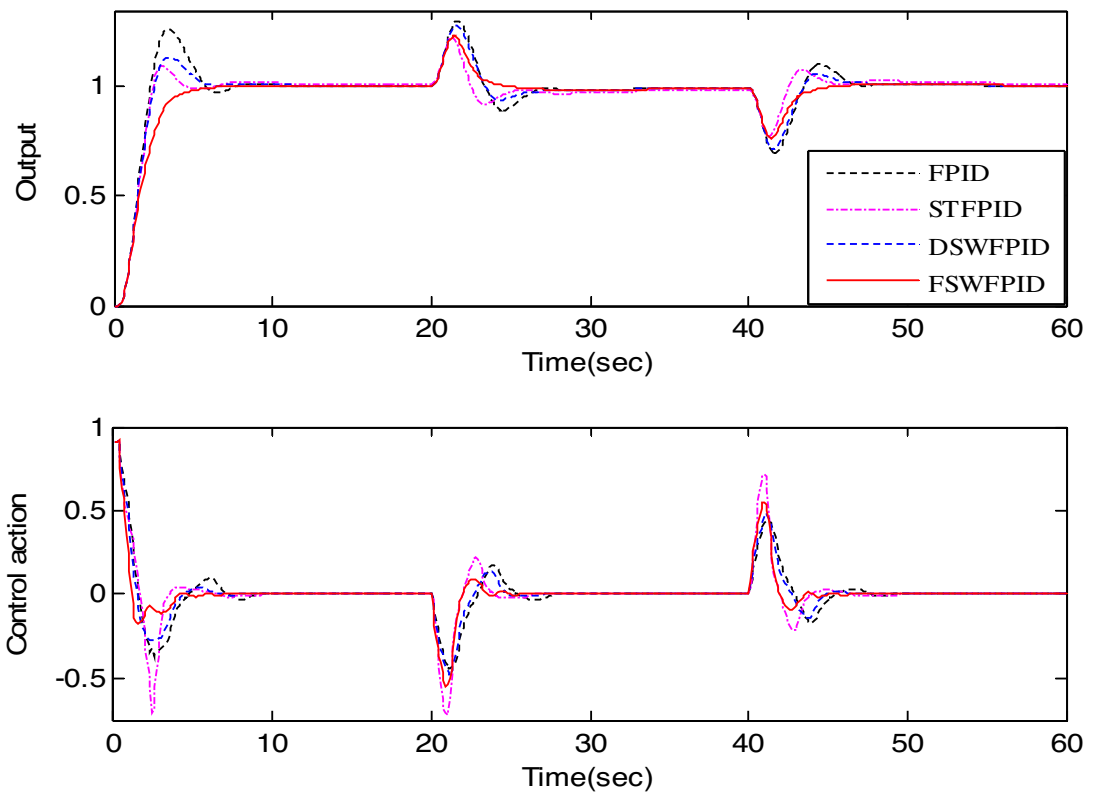

(a)
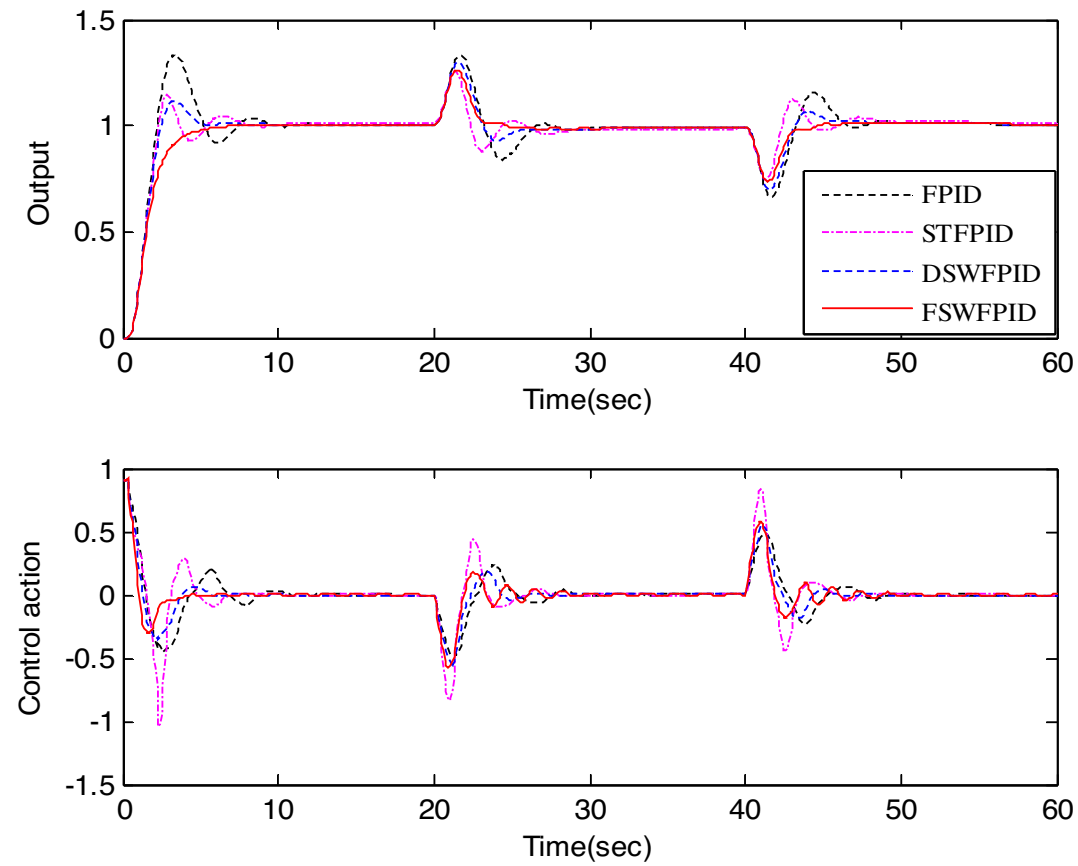

(b) 
Table 12 Performance analysis for Model IV

\begin{tabular}{|c|c|c|c|c|c|c|c|c|c|}
\hline Model & Rule & $L(s)$ & Controller & $\% O S$ & $t_{r}(s)$ & $t_{s}(s)$ & IAE & ITAE & TV \\
\hline \multirow[t]{16}{*}{ IV } & \multirow[t]{16}{*}{49} & \multirow[t]{4}{*}{0.05} & FPID & 19.8 & 2.4 & 7.8 & 3.53 & 60.06 & 0.42 \\
\hline & & & STFPID & 8.9 & 2.5 & 7.2 & 3.17 & 55.00 & 0.51 \\
\hline & & & DSWFPID & 14.7 & 2.5 & 7.2 & 3.33 & 56.17 & 0.38 \\
\hline & & & FSWFPID (proposed) & 0.0 & 7.1 & 7.1 & 2.99 & 41.40 & 0.36 \\
\hline & & \multirow[t]{4}{*}{0.1} & FPID & 20.8 & 2.4 & 8.6 & 3.70 & 60.50 & 0.43 \\
\hline & & & STFPID & 9.2 & 2.6 & 7.3 & 3.32 & 55.60 & 0.52 \\
\hline & & & DSWFPID & 11.3 & 2.7 & 6.8 & 3.34 & 53.47 & 0.37 \\
\hline & & & FSWFPID (proposed) & 0.0 & 6.6 & 6.6 & 3.09 & 41.80 & 0.36 \\
\hline & & \multirow[t]{4}{*}{0.2} & FPID & 26.4 & 2.4 & 10.5 & 3.95 & 65.01 & 0.47 \\
\hline & & & STFPID & 9.9 & 2.5 & 10.7 & 3.35 & 56.10 & 0.65 \\
\hline & & & DSWFPID & 13.7 & 2.6 & 7.6 & 3.50 & 56.20 & 0.42 \\
\hline & & & FSWFPID (proposed) & 0.0 & 6.7 & 6.7 & 3.10 & 42.3 & 0.43 \\
\hline & & \multirow[t]{4}{*}{0.3} & FPID & 33.4 & 2.2 & 11.0 & 4.30 & 73.00 & 0.62 \\
\hline & & & STFPID & 14.3 & 2.4 & 9.9 & 3.43 & 58.40 & 0.97 \\
\hline & & & DSWFPID & 11.6 & 2.5 & 7.5 & 3.34 & 55.50 & 0.52 \\
\hline & & & FSWFPID (proposed) & 0.0 & 7.4 & 7.4 & 3.08 & 43.40 & 0.64 \\
\hline
\end{tabular}

set point tracking are shown in Fig. 25a and load rejection responses are provided in Fig. 25b. Similar set of responses with 25 control rules are depicted in Fig. 26a and $b$, respectively. Real-time responses clearly substantiate the improved performance of the proposed FSWFPID in comparison with STFPID and DSWFPID. Superiority of FSWFPID is also validated from the listed values of performance indices of Table 17. Overshoot is completely eliminated in case of our proposed FSWFPID. IAE and ITAE values are found to be smaller for the proposed controller than the other reported controllers (STFPID and DSWFPID). Noise sensitivity of FSWFPID is also evaluated with addition of a measurement noise. Substantial noise signal with power 0.01 is incorporated to assess the efficacy of the proposed FSWFPID controller in the presence of unwanted noise during closedloop operation. Responses of the proposed FSWFPID for both 49 and 25 control rules in the presence of noise are depicted in Fig. 27a and b. From the responses of Fig. 27a and b, it is clear that the proposed FSWFPID has strong noise immunity and capable of exhibiting stable behaviour during both the transient and steady-state operating phases.

\section{Conclusion}

Here, a simple but robust tuning scheme with fuzzy rulebased set point weighting technique is proposed for an initially designed fuzzy PID controller. The most important feature of the proposed controller is that its functioning methodology is independent of the process model. Performance of the proposed tuning strategy is validated with well-known linear and nonlinear process models. Instantaneous value of the set point weighting factor is obtained based on expert defined 9 fuzzy rules depending on the instantaneous process change of error. The proposed methodology is found to be quite effective to provide acceptable performance with minimum overshoot during set point tracking as well as acceptable load variation. Efficacy of the proposed methodology has been justified through simulation study and real-time experimentation. Robustness of the proposed controller has also been observed in the presence of measurement noise. In future scope, number of fuzzy rules for fuzzy set point weighting may be increased towards further enhancement of the fuzzy PID controller. Moreover, similar strategy may also be adopted for Type-2 fuzzy controller and intuitionistic fuzzy control in noisy environment. 
Fig. 17 Responses and control actions for Model IV using 25 rules during set point response and with load variation for $\mathbf{a}$ $L=0.2 \mathrm{~s}, \mathbf{b} L=0.3 \mathrm{~s}$
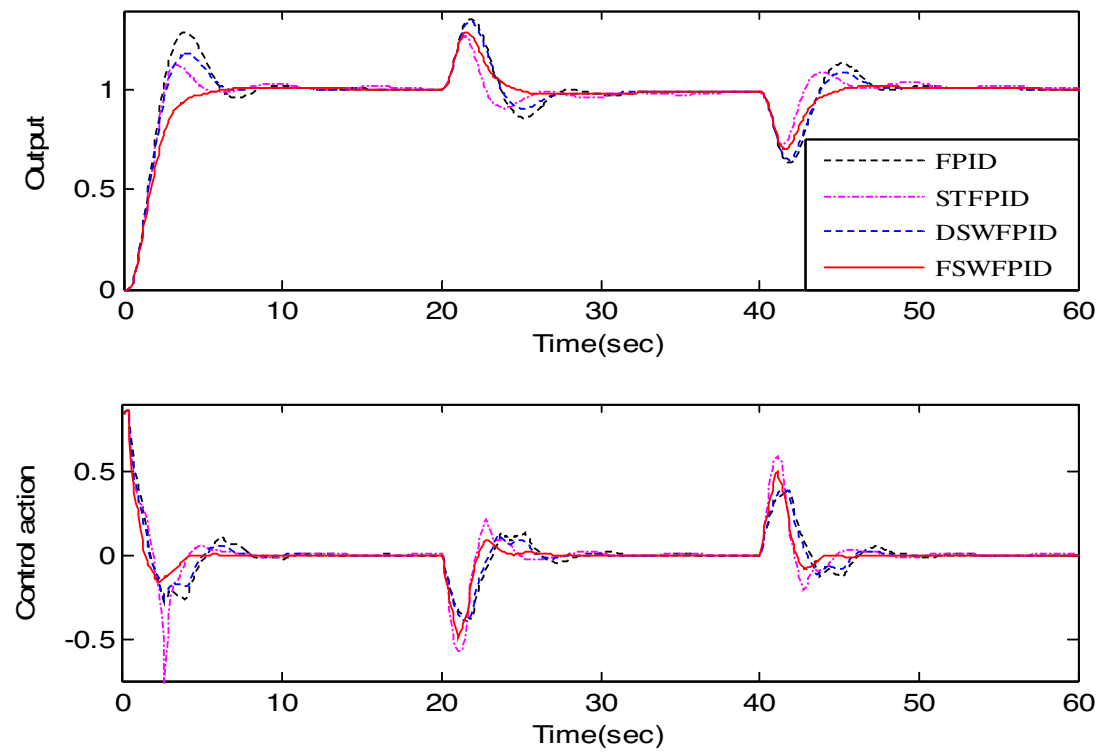

(a)
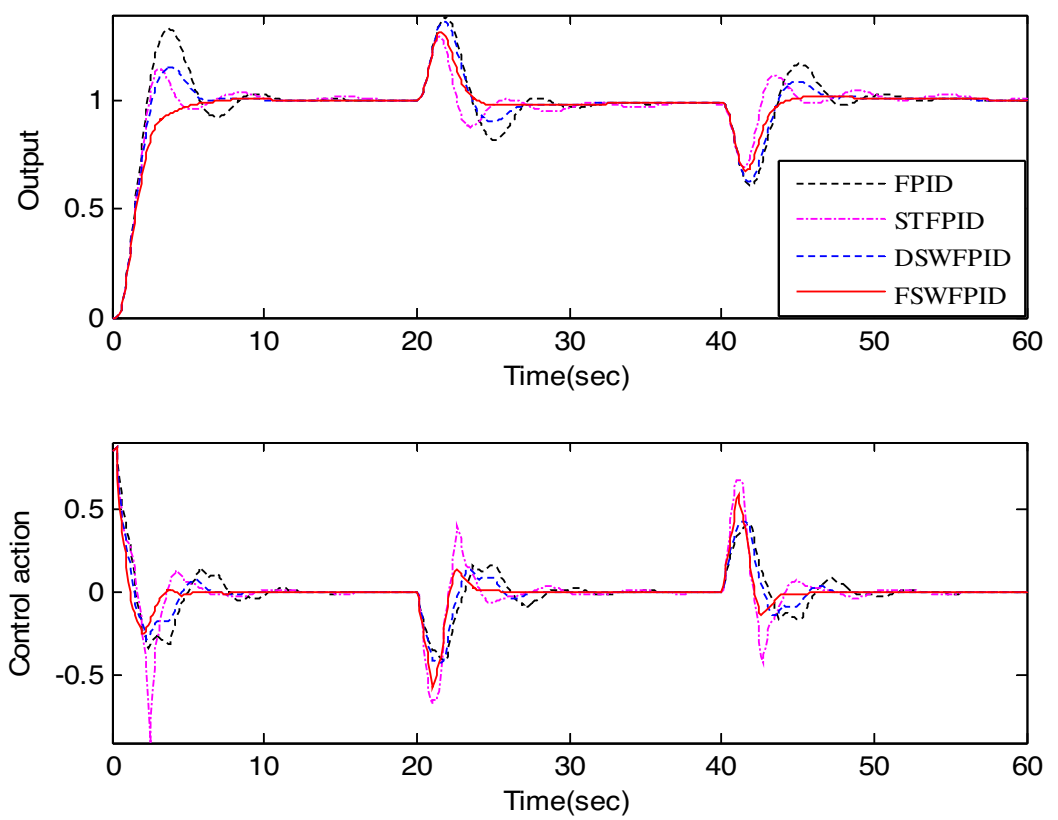

(b) 
Table 13 Performance analysis for Model IV

Fig. 18 Comparison among responses and control actions for Model IV with FSMC using 49 rules during set point response and with load variation for $\mathbf{a} L=0.1 \mathrm{~s}, \mathbf{b} L=0.3 \mathrm{~s}$

\begin{tabular}{|c|c|c|c|c|c|c|c|c|c|}
\hline Model & Rule & $L(s)$ & Controller & $\% O S$ & $t_{r}(s)$ & $t_{s}(s)$ & IAE & ITAE & TV \\
\hline \multirow[t]{16}{*}{ IV } & 25 & 0.05 & FPID & 24.1 & 2.5 & 12.2 & 4.28 & 78.06 & 0.42 \\
\hline & & & STFPID & 11.3 & 2.7 & 13.5 & 3.60 & 63.21 & 0.51 \\
\hline & & & DSWFPID & 19.2 & 2.7 & 12.1 & 4.10 & 73.48 & 0.44 \\
\hline & & & FSWFPID (proposed) & 0.0 & 6.8 & 6.8 & 3.52 & 55.71 & 0.32 \\
\hline & & 0.1 & FPID & 25.3 & 2.6 & 12.7 & 4.42 & 78.57 & 0.42 \\
\hline & & & STFPID & 11.7 & 2.7 & 14.2 & 3.70 & 63.68 & 0.52 \\
\hline & & & DSWFPID & 20.4 & 2.7 & 12.2 & 4.20 & 74.03 & 0.41 \\
\hline & & & FSWFPID (proposed) & 0.0 & 6.0 & 6.0 & 3.62 & 56.10 & 0.33 \\
\hline & & 0.2 & FPID & 29.4 & 2.5 & 16.1 & 4.74 & 85.20 & 0.45 \\
\hline & & & STFPID & 12.3 & 2.7 & 12.7 & 3.75 & 64.69 & 0.62 \\
\hline & & & DSWFPID & 17.6 & 2.7 & 12.0 & 4.25 & 74.91 & 0.41 \\
\hline & & & FSWFPID (proposed) & 0.0 & 6.3 & 6.3 & 3.63 & 56.57 & 0.38 \\
\hline & & 0.3 & FPID & 33.4 & 2.4 & 15.8 & 5.12 & 95.87 & 0.54 \\
\hline & & & STFPID & 15.1 & 2.5 & 11.1 & 3.76 & 66.12 & 0.81 \\
\hline & & & DSWFPID & 15.8 & 2.7 & 10.1 & 4.14 & 75.65 & 0.43 \\
\hline & & & FSWFPID (proposed) & 0.0 & 7.0 & 7.0 & 3.53 & 56.11 & 0.46 \\
\hline
\end{tabular}
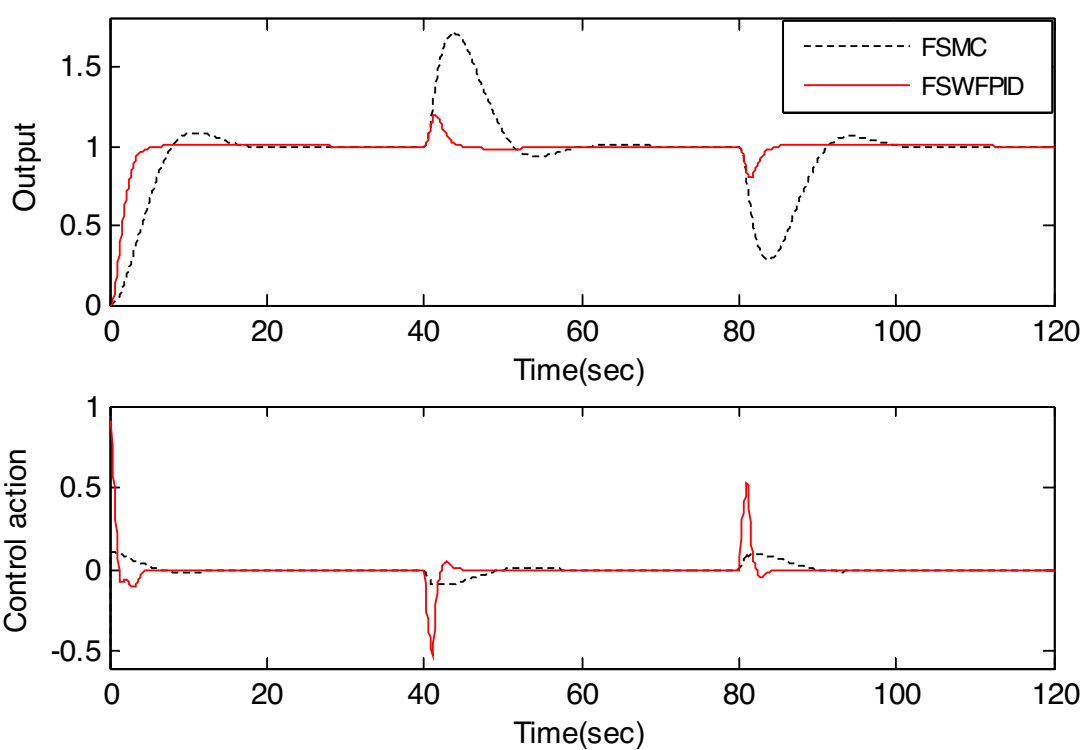

(a)
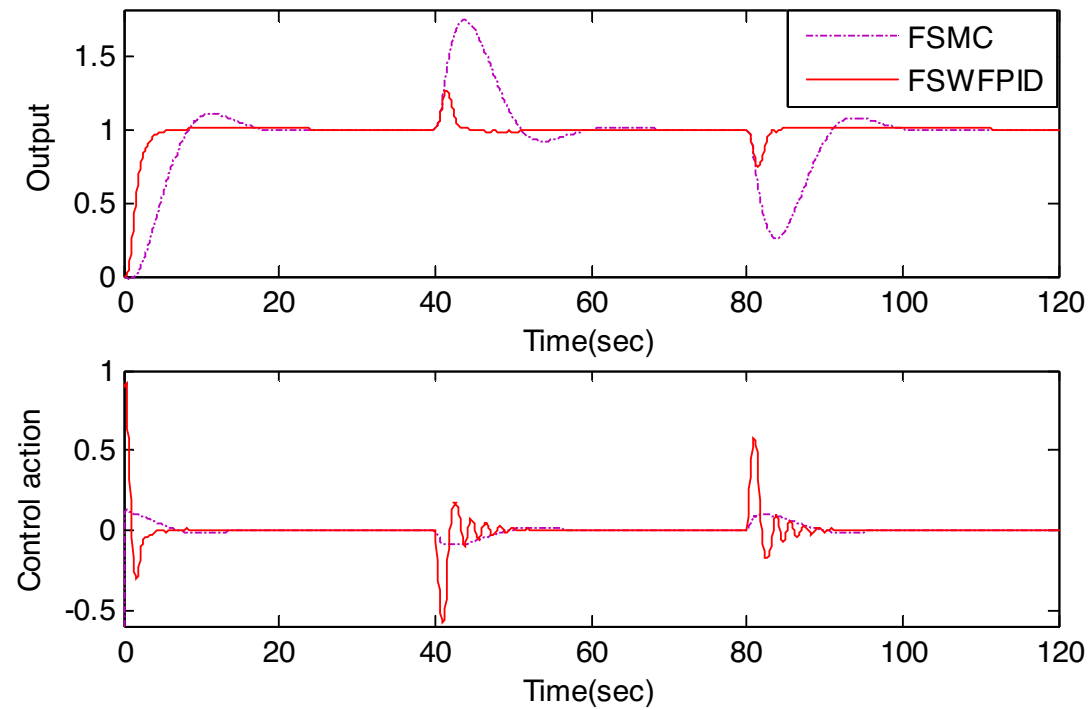

(b) 
Fig. 19 Comparison among responses and control actions for Model IV with FSMC using 25 rules during set point response and with load variation for $\mathbf{a} L=0.1 \mathrm{~s}, \mathbf{b} L=0.3 \mathrm{~s}$
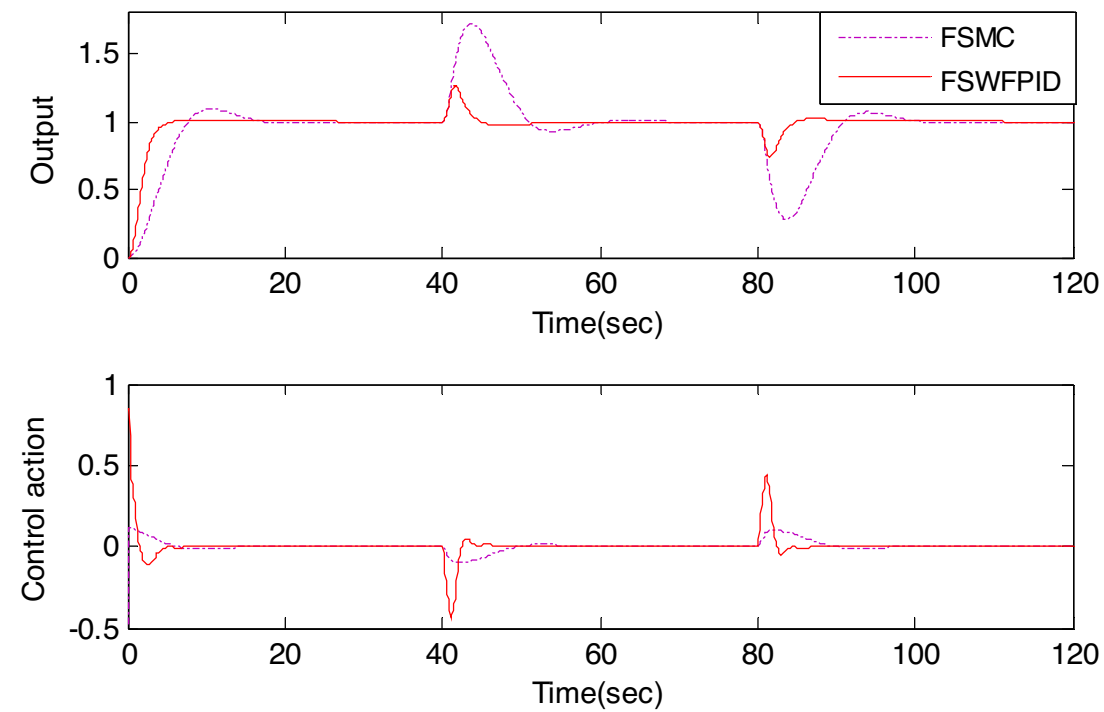

(a)
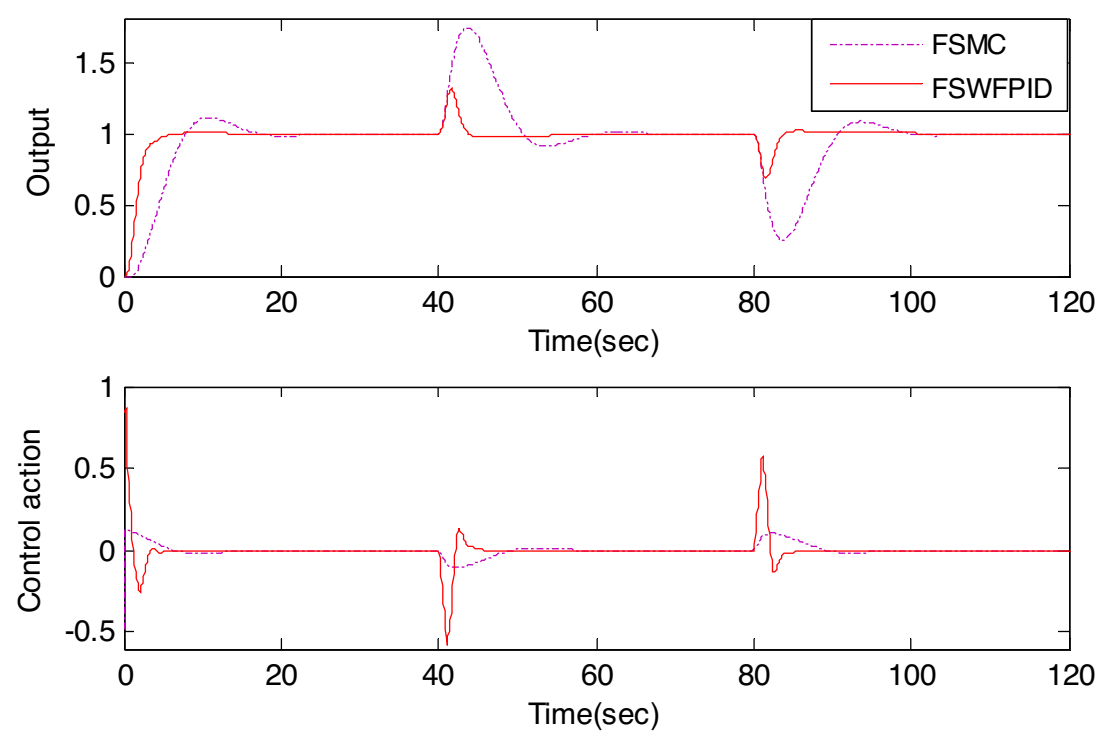

(b)
Table 14 Performance analysis for Model IV

\begin{tabular}{|c|c|c|c|c|c|c|c|c|c|}
\hline Model & Rule & $L(s)$ & Controller & $\% O S$ & $t_{r}(s)$ & $t_{s}(s)$ & IAE & ITAE & TV \\
\hline \multirow[t]{8}{*}{ IV } & \multirow[t]{4}{*}{49} & \multirow[t]{2}{*}{0.1} & FSMC & 8.6 & 8.1 & 28.0 & 14.41 & 650.2 & 0.29 \\
\hline & & & FSWFPID (proposed) & 0.0 & 6.6 & 9.3 & 3.23 & 85.25 & 0.36 \\
\hline & & \multirow[t]{2}{*}{0.3} & FSMC & 10.4 & 8.4 & 24.8 & 15.57 & 681.8 & 0.3 \\
\hline & & & FSWFPID (proposed) & 0.0 & 7.4 & 9.5 & 3.2 & 88.71 & 0.6 \\
\hline & \multirow[t]{4}{*}{25} & \multirow[t]{2}{*}{0.1} & FSMC & 9.4 & 7.8 & 27.7 & 14.19 & 642.6 & 0.27 \\
\hline & & & FSWFPID (proposed) & 0.0 & 6.0 & 10.9 & 3.8 & 112.5 & 0.33 \\
\hline & & \multirow[t]{2}{*}{0.3} & FSMC & 11.4 & 8.0 & 26.8 & 15.24 & 674.9 & 0.27 \\
\hline & & & FSWFPID (proposed) & 0.0 & 7.0 & 7.9 & 3.67 & 113.8 & 0.45 \\
\hline
\end{tabular}


Fig. 20 Responses and control actions for Model V using 49 rules during set point response and with load variation for a $L=0.2 \mathrm{~s}, \mathbf{b} L=0.3 \mathrm{~s}$
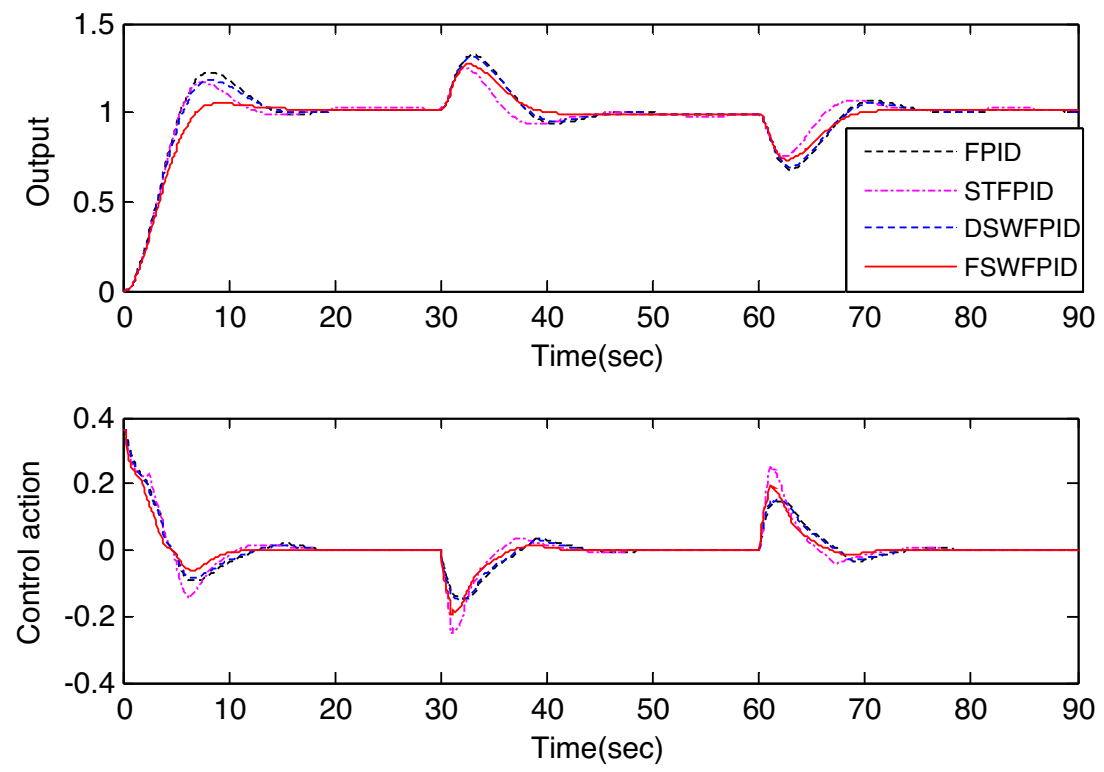

(a)
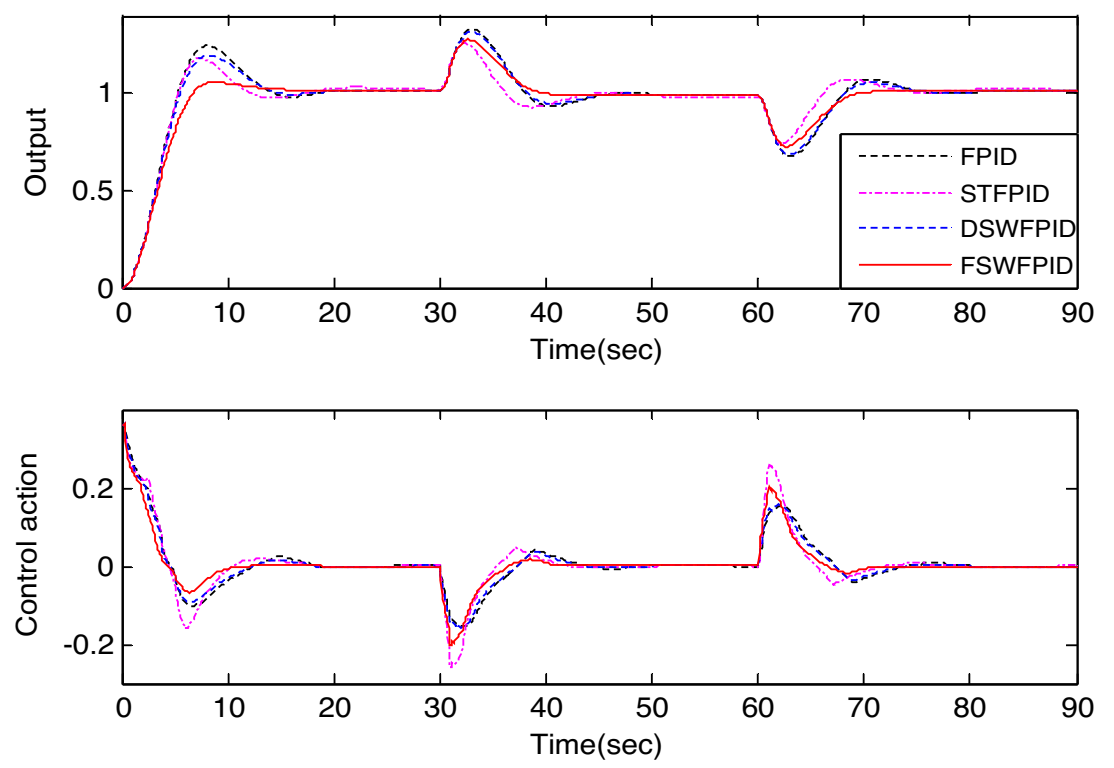

(b) 
Fig. 21 Responses and control actions for Model V using 25 rules during set point response and with load variation for a $L=0.2 \mathrm{~s}, \mathbf{b} L=0.3 \mathrm{~s}$
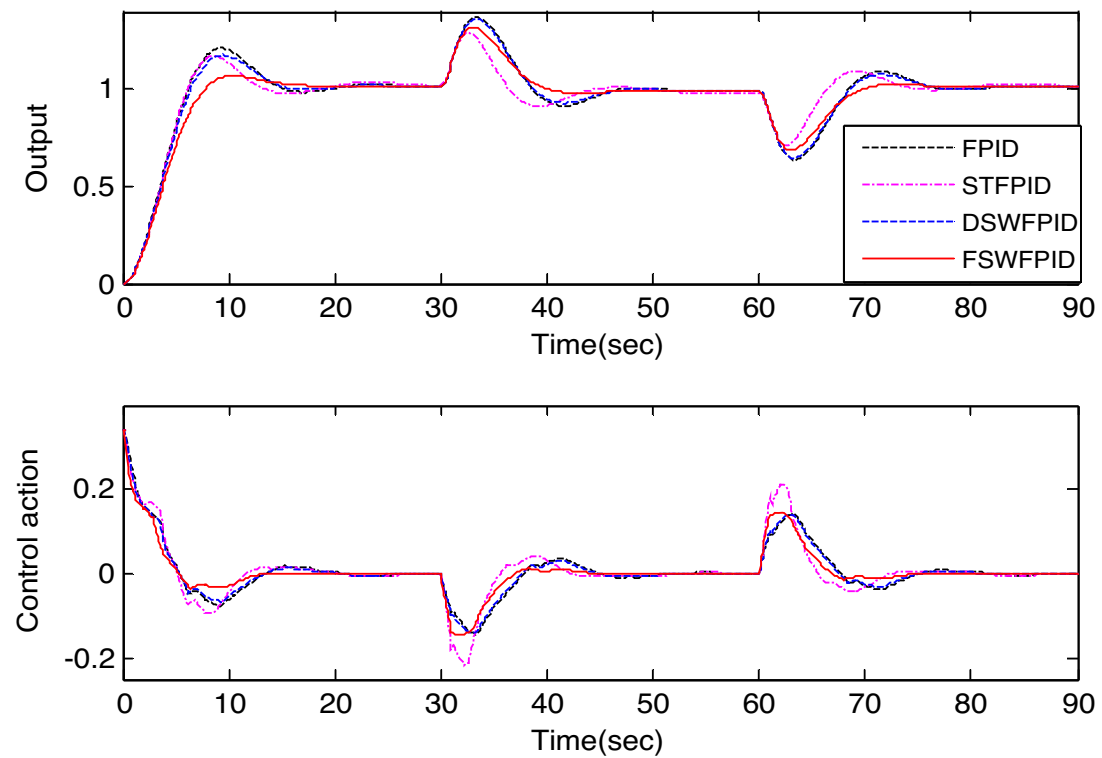

(a)
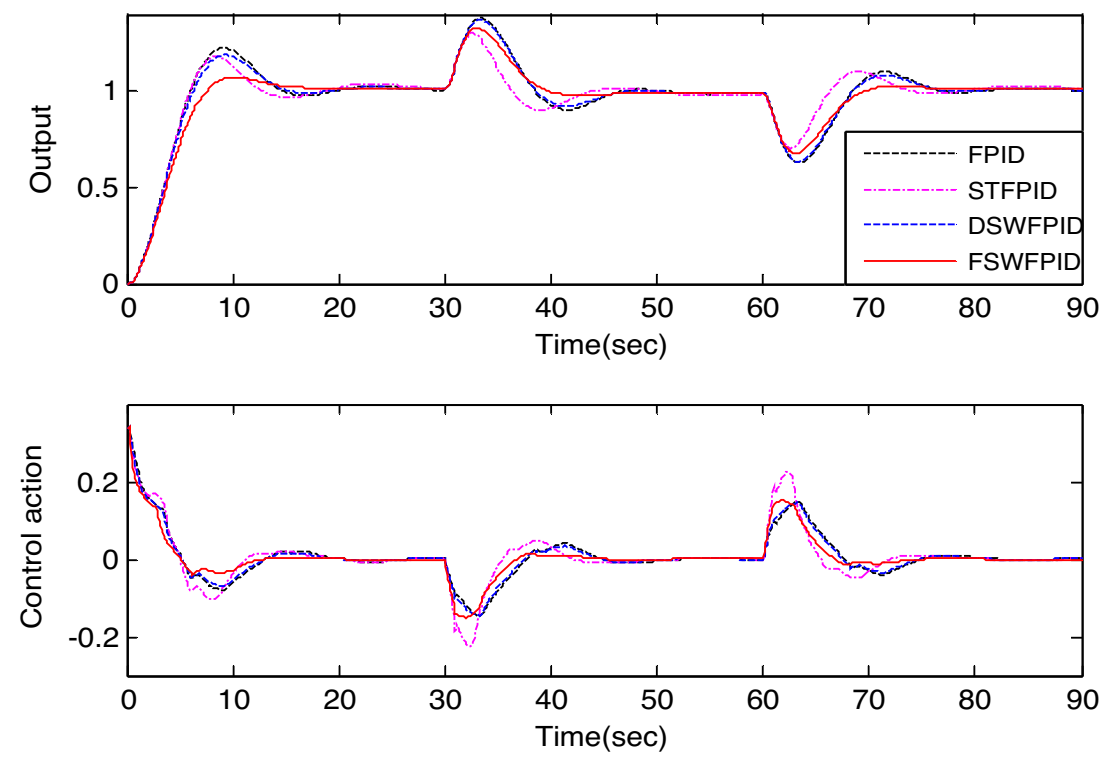

(b) 
Fig. 22 Comparison among responses and control actions for Model V with FSMC using 49 rules during set point response and with load variation for $\mathbf{a} L=0.2 \mathrm{~s}, \mathbf{b} L=0.3 \mathrm{~s}$
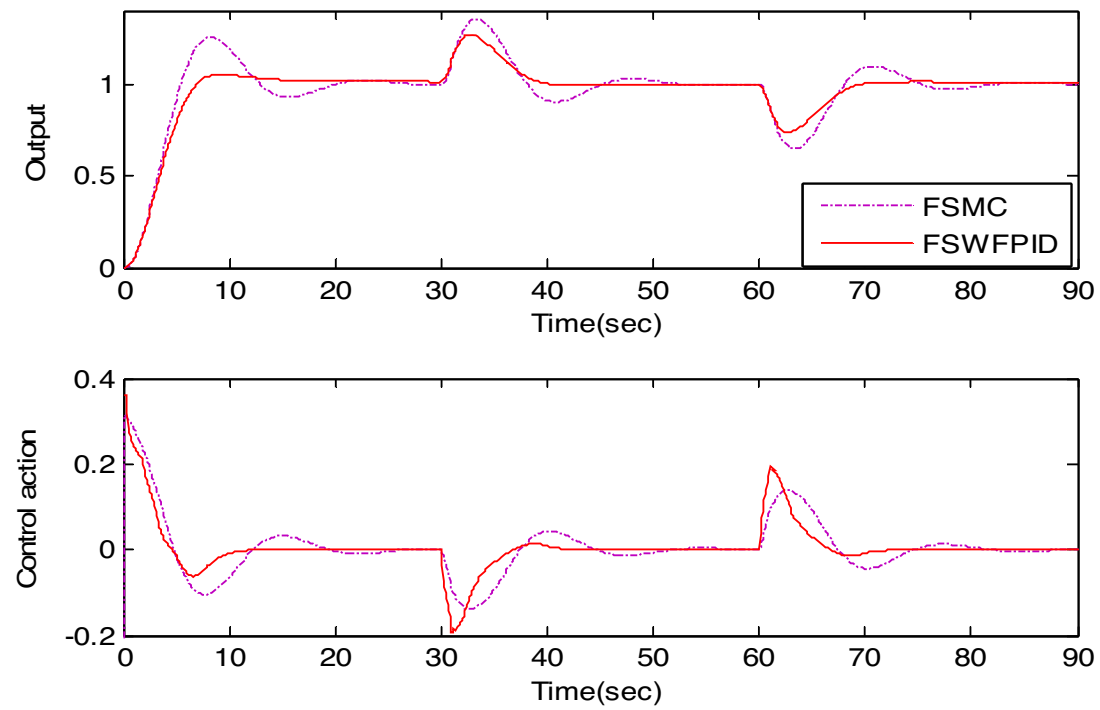

(a)
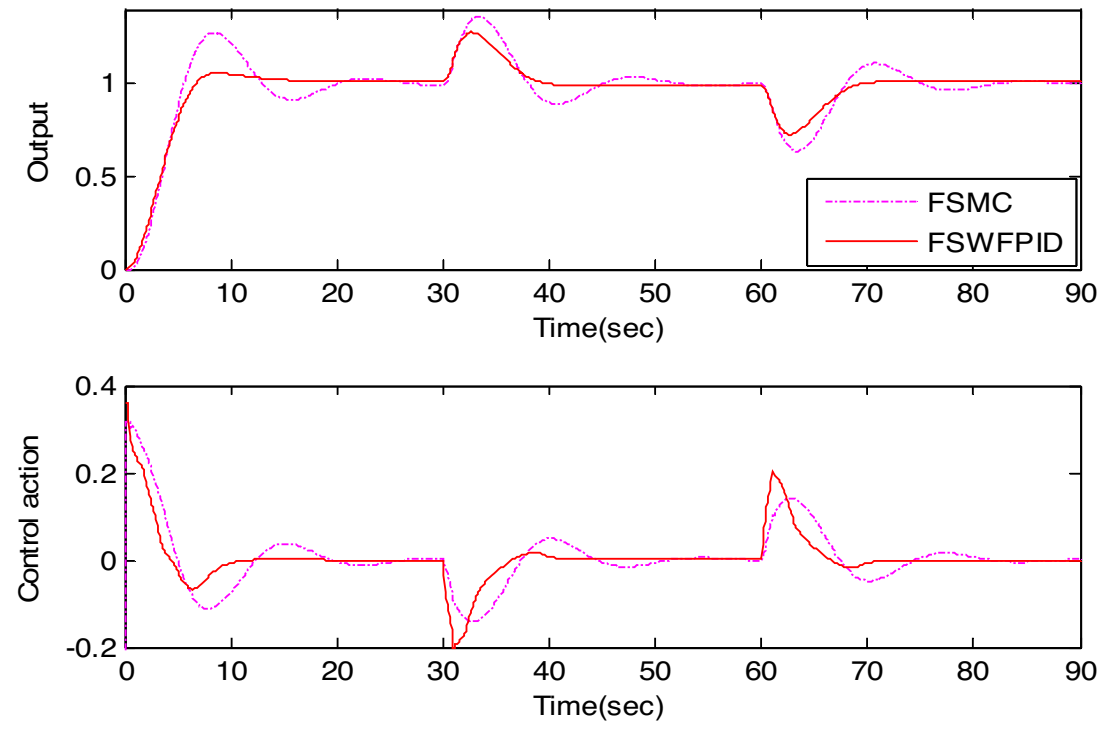

(b) 
Fig. 23 Comparison among responses and control actions for Model V with FSMC using

25 rules during set point response and with load variation for $\mathbf{a} L=0.2 \mathrm{~s}, \mathbf{b} L=0.3 \mathrm{~s}$
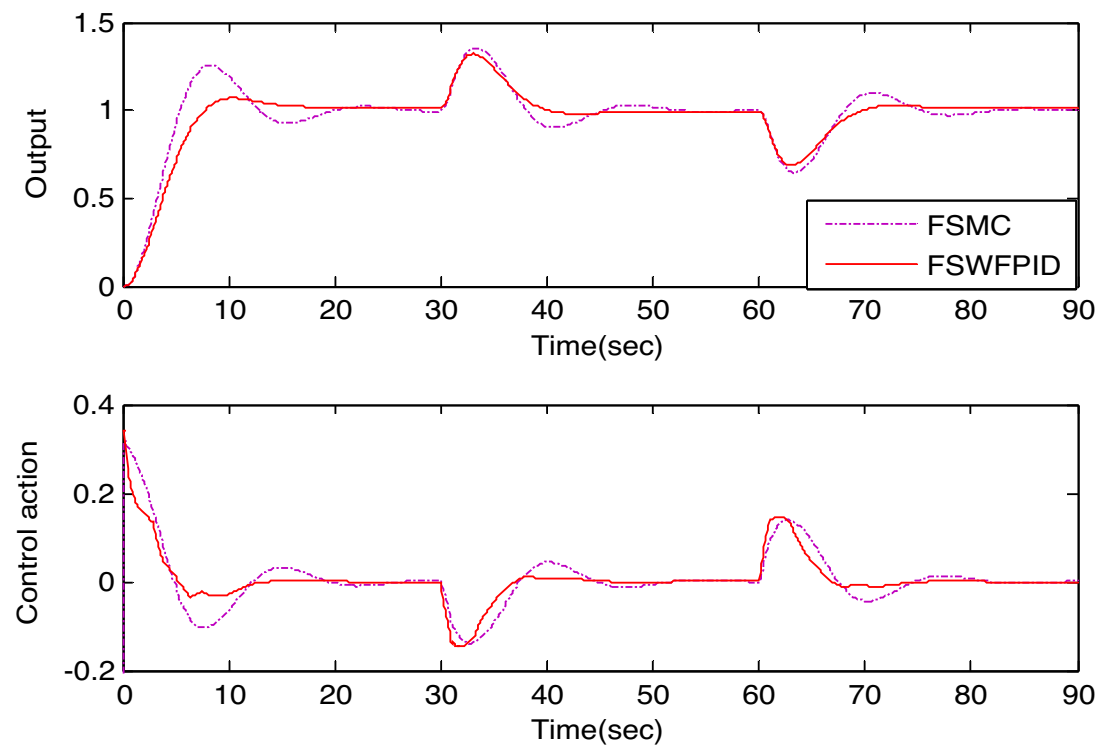

(a)
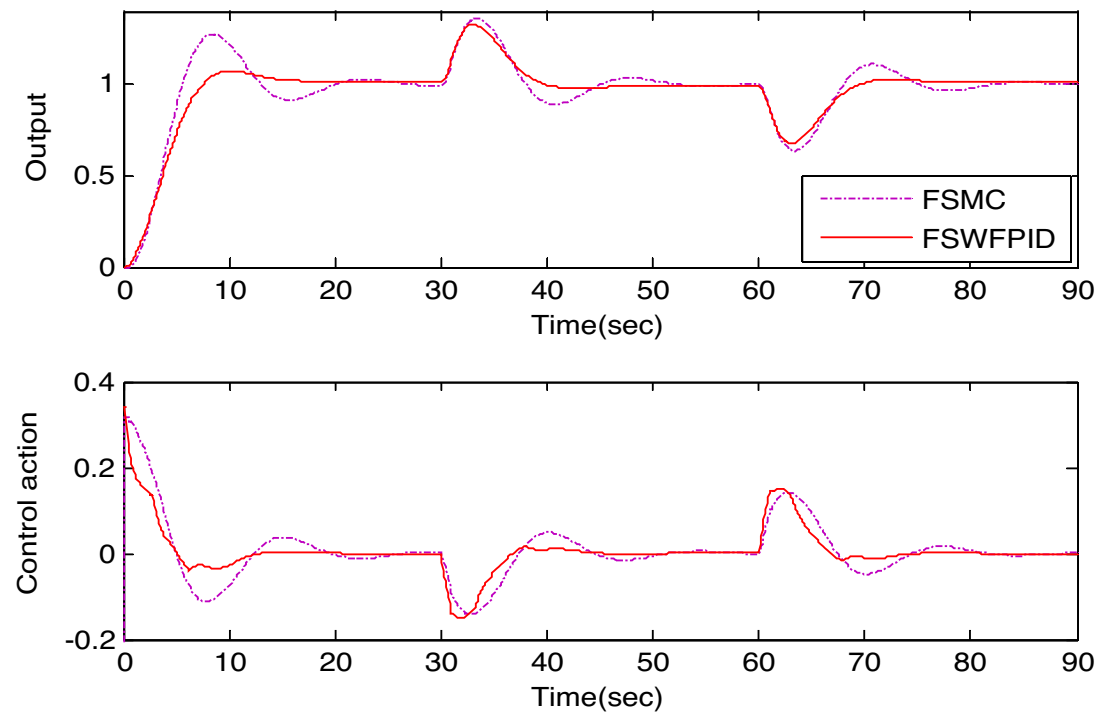

(b) 
Table 15 Performance analysis for Model V

\begin{tabular}{|c|c|c|c|c|c|c|c|c|c|}
\hline Model & Rule & $L(\mathrm{~s})$ & Controller & $\% \mathrm{OS}$ & $t_{r}(s)$ & $t_{s}(s)$ & IAE & ITAE & TV \\
\hline \multirow[t]{15}{*}{ V } & 49 & 0.1 & FPID & 20.8 & 5.8 & 20.5 & 8.19 & 209.9 & 0.19 \\
\hline & & & STFPID & 15.8 & 5.8 & 30.0 & 7.13 & 174.0 & 0.24 \\
\hline & & & DSWFPID & 16.8 & 5.8 & 20.5 & 7.87 & 199.3 & 0.19 \\
\hline & & & FSMC & 21.4 & 5.8 & 26.0 & 8.89 & 237.1 & 0.41 \\
\hline & & & FSWFPID (proposed) & 4.7 & 7.2 & 16.0 & 7.05 & 166.5 & 0.19 \\
\hline & & 0.2 & FPID & 22.7 & 5.5 & 24.2 & 8.4 & 214.4 & 0.2 \\
\hline & & & STFPID & 16.6 & 5.5 & 27.1 & 7.24 & 175.1 & 0.25 \\
\hline & & & DSWFPID & 18.3 & 5.5 & 21.3 & 8.03 & 203.0 & 0.19 \\
\hline & & & FSMC & 23.2 & 5.8 & 30.0 & 9.27 & 249.5 & 0.41 \\
\hline & & & FSWFPID (proposed) & 5.2 & 7.0 & 11.2 & 7.09 & 167.2 & 0.19 \\
\hline & & 0.3 & FPID & 24.5 & 5.6 & 24.0 & 8.51 & 218.6 & 0.21 \\
\hline & & & STFPID & 18.2 & 5.6 & 30.0 & 7.25 & 175.9 & 0.27 \\
\hline & & & DSWFPID & 19.8 & 5.6 & 20.5 & 8.10 & 206.4 & 0.20 \\
\hline & & & FSMC & 25.2 & 6.0 & 30.0 & 9.98 & 265.0 & 0.42 \\
\hline & & & FSWFPID (proposed) & 5.7 & 6.8 & 15.1 & 7.04 & 167.3 & 0.20 \\
\hline
\end{tabular}

Table 16 Performance analysis for Model V

\begin{tabular}{|c|c|c|c|c|c|c|c|c|c|}
\hline Model & Rule & $L(s)$ & Controller & $\% O S$ & $t_{r}(s)$ & $t_{s}(s)$ & IAE & ITAE & TV \\
\hline \multirow[t]{15}{*}{ V } & 25 & 0.1 & FPID & 19.6 & 6.6 & 27.2 & 9.29 & 255.5 & 0.2 \\
\hline & & & STFPID & 16.2 & 6.6 & 30.0 & 7.90 & 197.0 & 0.23 \\
\hline & & & DSWFPID & 16.3 & 6.6 & 27.0 & 9.00 & 243.7 & 0.19 \\
\hline & & & FSMC & 23.5 & 5.5 & 26.0 & 8.95 & 242.3 & 0.37 \\
\hline & & & FSWFPID (proposed) & 6.4 & 8.0 & 17.3 & 8.1 & 204.8 & 0.17 \\
\hline & & 0.2 & FPID & 21.1 & 6.5 & 27.2 & 9.55 & 263.9 & 0.20 \\
\hline & & & STFPID & 17.2 & 6.5 & 30.0 & 8.10 & 201.4 & 0.24 \\
\hline & & & DSWFPID & 17.6 & 5.5 & 27.0 & 9.19 & 249.8 & 0.19 \\
\hline & & & FSMC & 25.5 & 7.8 & 30.0 & 9.38 & 256.1 & 0.38 \\
\hline & & & FSWFPID (proposed) & 6.9 & 6.3 & 17.4 & 8.20 & 207.4 & 0.17 \\
\hline & & 0.3 & FPID & 22.5 & 6.3 & 26.9 & 9.73 & 273.3 & 0.21 \\
\hline & & & STFPID & 18.1 & 6.3 & 30.0 & 8.20 & 208.4 & 0.25 \\
\hline & & & DSWFPID & 18.8 & 6.3 & 26.5 & 9.29 & 256.2 & 0.19 \\
\hline & & & FSMC & 27.7 & 5.7 & 30.0 & 10.04 & 272.9 & 0.39 \\
\hline & & & FSWFPID (proposed) & 7.3 & 7.6 & 16.9 & 8.20 & 209.5 & 0.18 \\
\hline
\end{tabular}




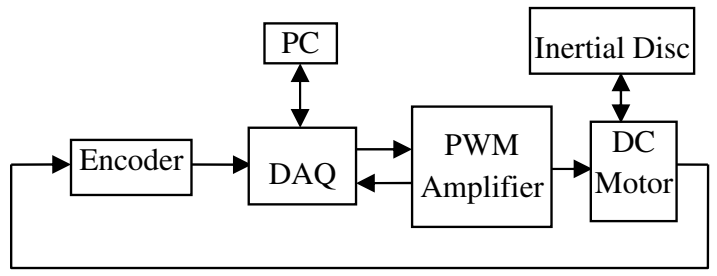

(a)

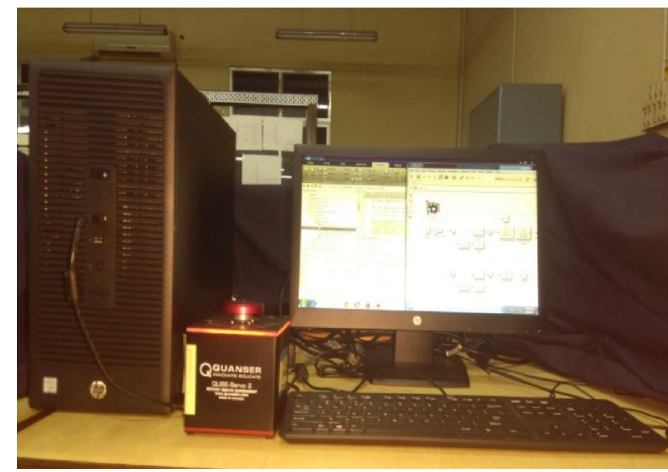

(b)

Fig. 24 a Block schematic for experimental setup of Quanser QUBE-Servo 2. b Snapshot of experimental setup of Quanser QUBE-Servo 2
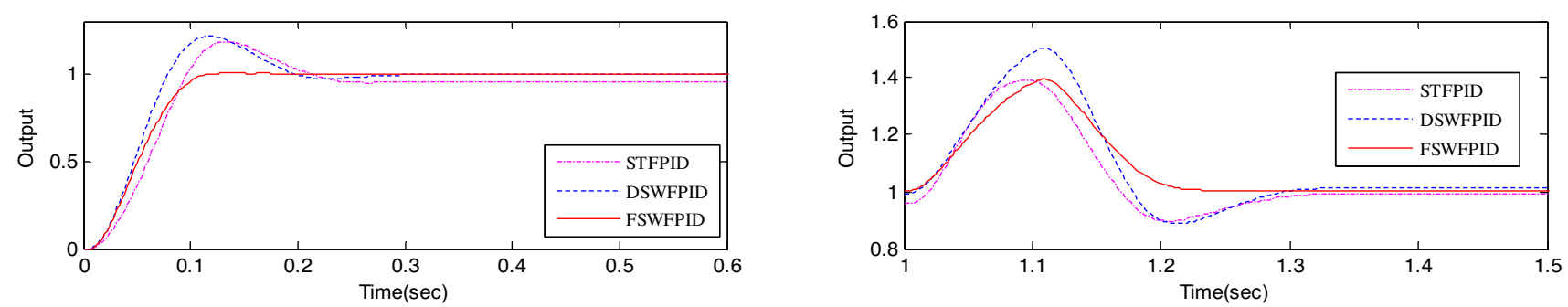

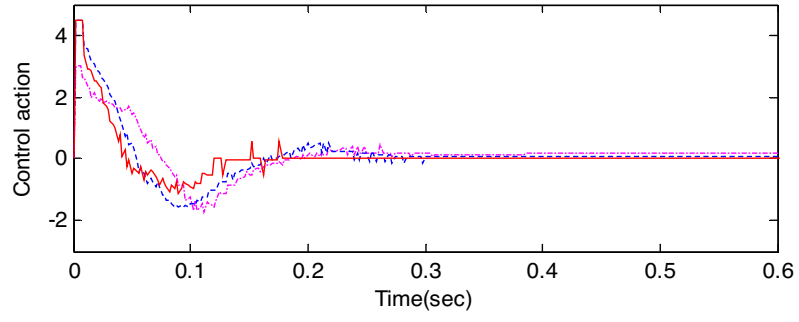

(a)

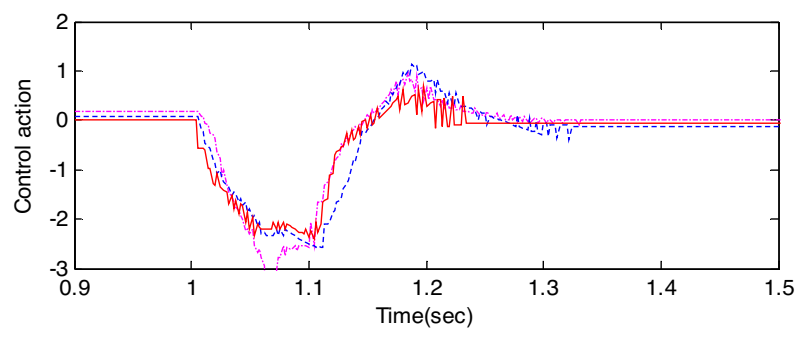

(b)

Fig. 25 Responses and control actions for Quanser QUBE-Servo 2 using 49 rules during a set point tracking and b load recovery 

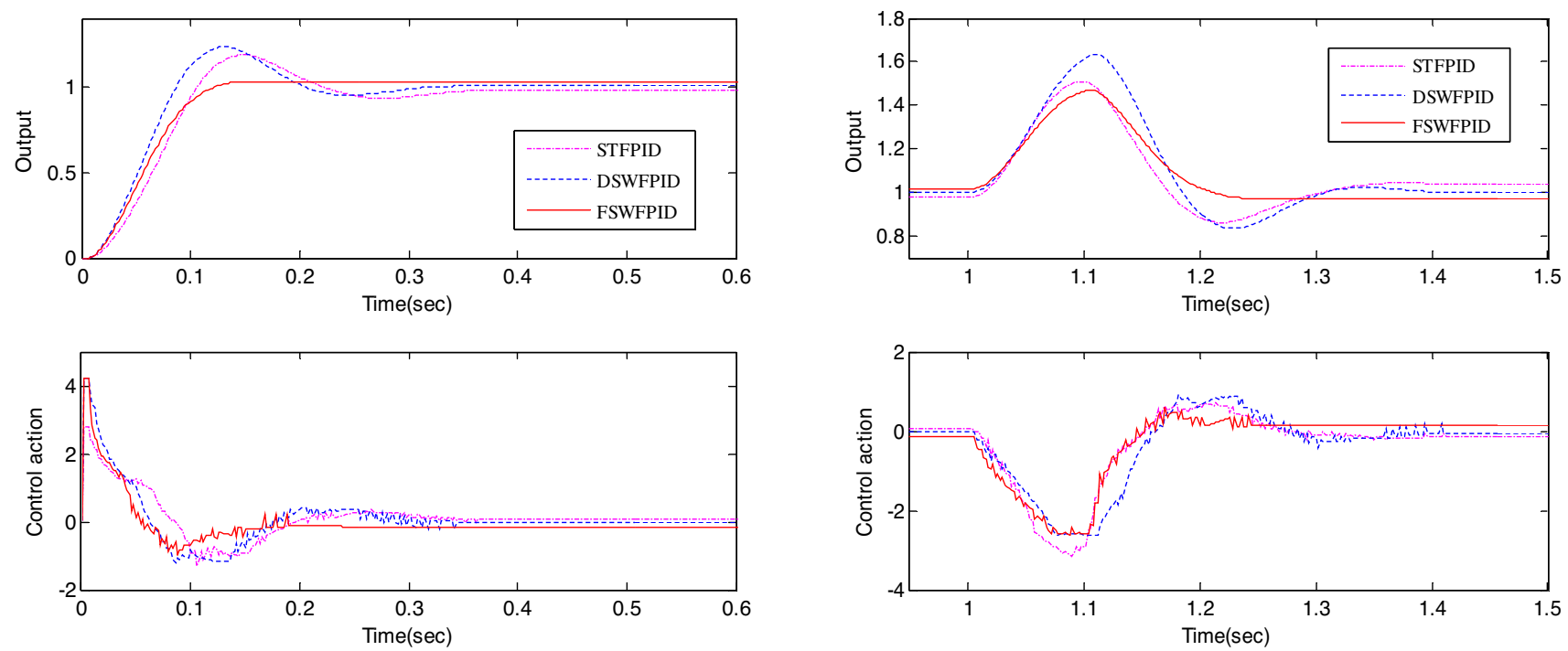

(a)

(b)

Fig. 26 Responses and control actions for Quanser QUBE-Servo 2 using 25 rules a during set point tracking and $\mathbf{b}$ load recovery

Table 17 Performance analysis for real-time experimentation with Quanser QUBE-Servo 2

\begin{tabular}{lllllll}
\hline Rule & Controller & $\%$ OS & $t_{r}(s)$ & IAE & ITAE & TV \\
\hline 49 & FPID & 31.0 & 0.08 & 0.14 & 0.083 & 0.09 \\
& STFPID & 18.1 & 0.10 & 0.16 & 0.080 & 0.07 \\
& DSWFPID & 21.5 & 0.08 & 0.13 & 0.082 & 0.08 \\
& FSWFPID (proposed) & 0.0 & 0.12 & 0.09 & 0.051 & 0.07 \\
& FPID & 30.0 & 0.08 & 0.16 & 0.13 & 0.08 \\
& STFPID & 18.4 & 0.11 & 0.18 & 0.12 & 0.07 \\
& DSWFPID & 23.0 & 0.09 & 0.15 & 0.11 & 0.08 \\
& FSWFPID (proposed) & 0.0 & 0.12 & 0.15 & 0.09 & 0.07 \\
\hline
\end{tabular}
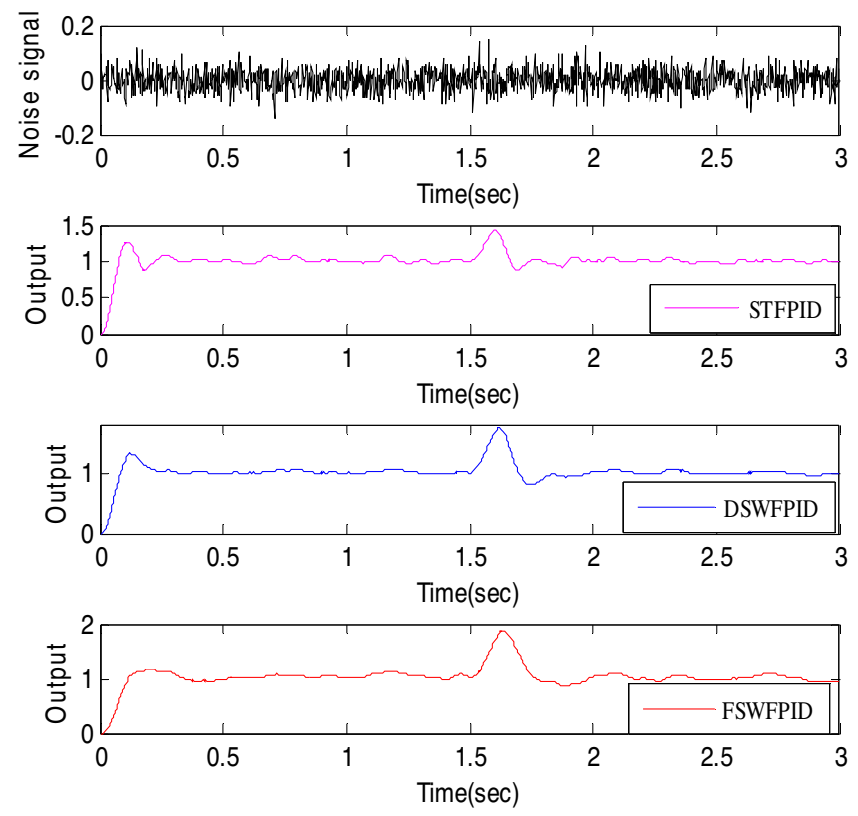

(a)
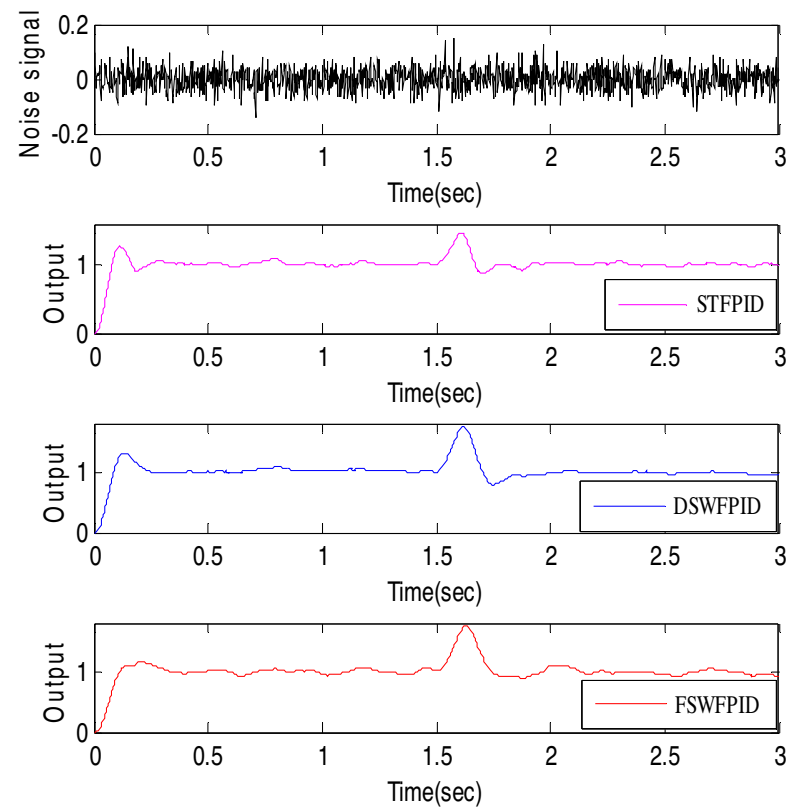

(b)

Fig. 27 Responses of Quanser QUBE-Servo 2 for STFPID, DSWFPID and FSWFPID along with noise signal for a 49 and $\mathbf{b} 25$ control rules 


\section{Declarations}

Conflict of interest On behalf of all authors, the corresponding author states that there is no conflict of interest.

Open Access This article is licensed under a Creative Commons Attribution 4.0 International License, which permits use, sharing, adaptation, distribution and reproduction in any medium or format, as long as you give appropriate credit to the original author(s) and the source, provide a link to the Creative Commons licence, and indicate if changes were made. The images or other third party material in this article are included in the article's Creative Commons licence, unless indicated otherwise in a credit line to the material. If material is not included in the article's Creative Commons licence and your intended use is not permitted by statutory regulation or exceeds the permitted use, you will need to obtain permission directly from the copyright holder. To view a copy of this licence, visit http://creativecommons.org/licenses/by/4.0/.

\section{References}

1. Mamdani EH (1975) An experiment in linguistic synthesis with a fuzzy logic controller. Int J Man-Mach Stud 7(1):1-13

2. Sugeno M (1985) Industrial applications of fuzzy control. Elsevier, Amsterdam, 978-0-444-87829-8

3. Jantzen J (2013) Foundations of fuzzy control - A practical approach. Wiley, West Sussex. https://doi.org/10.1002/9781118535608

4. Driankov D, Hellendron H, Reinfrank M (1993) An introduction to fuzzy control. Springer-Verlag, New York. https://doi.org/10. 1007/978-3-662-11131-4

5. Patil NJ, Chile RH, Waghmare LM (2013) A new approach to adaptive fuzzy PI controller using output scaling factor and reference models. Control Intell Syst 41(1). https://doi.org/10.2316/ Journal.201.2013.1.201-2277

6. Victor J, Dourado A (1997) Adaptive scaling factors algorithm for the fuzzy logic controller. In: Proceedings of the IEEE international conference on fuzzy systems (FUZZ_IEEE'97), vol 2. https://doi.org/10.1109/FUZZY.1997.622848

7. Pradhan PC, Sahu RK, Panda S (2016) Firefly algorithm optimized fuzzy PID controller for AGC of multi-area multi-source power systems with UPFC and SMES. Eng Sci Technol an Int J 19(1):338354. https://doi.org/10.1016/j.jestch.2015.08.00

8. Bousserhane I, Hazzab A, Rahli M, Kamli M, Mazari B (2006) Adaptive PI controller using fuzzy system optimized by genetic algorithm for induction motor control. Int Power Electron Congr (CIEP)-IEEE Xplore. https://doi.org/10.1109/CIEP.2006.312162

9. Uddin MN, Radwan TS, Rahman MA (2007) Fuzzy logic based position control of a PMSM servo drive. Control Intell Syst 35(4):293-299

10. Seborg DE, Edgar TF, Mellichamp DA (2004) Process dynamics and control, 2nd edn. Wiley, New York, 978-1-119-28595-3

11. Åstrom KJ, Hägglund T (2004) Revisiting the Ziegler-Nicholes step response method for PID control. J Process Control 14(6):635-650

12. Åstrom KJ, Hang CC, Persson P, Ho WK (1992) Towards intelligent PID control. Automatica 28(1):1-9

13. Hang CC, Cao L (1996) Improvement of transient response by means of variable set point weighting. IEEE Trans Ind Electron 43(4):477-484

14. Mantz RJ (2012) A PI controller with dynamic set point weighting for nonlinear processes. In: Procedings IFAC conference on advances in PID control, PID'12, Brescia (Italy), vol 45, no 3, pp 512-517. https://doi.org/10.3182/20120328-3-IT-3014.00087

15. Sree RP, Chidambaram M (2004) Simple method of calculating set point weighting parameter for unstable systems with a zero. Comput Chem Eng 28(11):2433-2437
16. Jeng JC, Fu EP (2015) Closed-loop tuning of set point-weighted proportional-integral-derivative controllers for stable, integrating, and unstable processes: a unified data-based method. Ind Eng Chem Res 54(3):1041-1058

17. Chen CC, Huang HP, Liaw HJ (2008) Set point weighted PID controller tuning for time-delayed unstable processes. Ind Eng Chem Res 47(18):6983-6990

18. Visioli A (1999) Fuzzy logic based set point weight tuning of PID controllers. IEEE Trans Syst Man Cybern 29(6):587-592

19. Mudi RK, Dey C (2011) Performance improvement of PI controllers through dynamic set point weighting. ISA Trans 50(2):220-230

20. Dey C, Mudi RK, Lee TT (2009) Dynamic set point weighted PID controller. Mechatron Syst Control (formerly Control Intell Syst) 37(4):212-219. https://doi.org/10.2316/Journal.201.2009.4. 201-2066

21. Mitra P, Dey C, Mudi RK (2017) Dynamic set point weighting for fuzzy PID controller. Control Intell Syst 45(3):142-153

22. Mitra P, Dey C, Mudi RK (2012) Fuzzy PI controller with dynamic set point weighting. In: Proceedings of the international conference on Frontiers of intelligent computing: theory and applications (FICTA), AISC 199, pp 51-58. https://doi.org/10.1007/ 978-3-642-35314-7_7

23. Mitra P, Dey C, Mudi RK (2013) Dynamic set point weighted fuzzy PID controller. In: Proceedings IEEE symposium on computational and business intelligence (ISCBI), pp 107-110. https://doi. org/10.1109/ISCBI.2013.29

24. Mudi RK, Pal NR (1997) A robust self-tuning scheme for PI and PD type fuzzy controllers. IEEE Trans Fuzzy Syst 7(1):2-16

25. Dey C, Mudi RK, Mitra P (2012) A self-tuning fuzzy PID controller with real time implementation on position control system. In: Proceedings. IEEE, international conference on emerging applications of information technology (EAIT), pp 32-35. https://doi. org/10.1109/EAIT.2012.6407855

26. Prasad KMA, Unnikrishnan A, Nair U (2016) Fuzzy sliding mode control of a switched reluctance motor. J Procedia Technol 25:735-742

27. Baba Y, Bouzi M, Lagrat I, Derri M (2015) Design of adaptive fuzzy sliding mode control for a traveling-wave ultrasonic motor. Int J Eng Res Technol (IJERT), 4(9), p 625-629, ISSN (Online): 2278-0181

28. Huang H, Bhuiyan ZA, Tu Q, Jiang C, Xue J, Ming P, Li P (2019) Fuzzy sliding mode control of servo control system based on variable speeding approach rate. J Soft Comput 23:1347713487. https://doi.org/10.1007/s00500-019-03886-8

29. Palm R (1999) Fuzzy Sliding mode controller with fuzzy inputs. In: Proceedings. IFAC conference, 32(2), p 8619-8624, https:// doi.org/10.1016/S1474-6670(17)57470-4

30. Butcher JC (2008) Numerical methods for ordinary differential equations, 2nd edn. Wiley, West Sussex

31. Documentation for the Quanser QUBE-Servo 2, Canada: Quanser, 2010

32. Veronesi M, Visioli A (2010) Performance assessment and retuning of PID controllers for integral processes. J Process Control 20(3): 261-269. https://doi.org/10.1016/j.jprocont.2009.12.007

33. Jeng JC, Fu EP (2015) Closed-loop tuning of set-point-weighted proportional-integral-derivative controllers for stable, integrating, and unstable processes: a unified data-based method. J Ind Eng Chem Res 54:1041-1058

34. Kos T, Huba M, Vrancic D (2020) "Parametric and nonparametric PID controller tuning method for integrating processes based on magnitude optimum. J Appl Sci. https://doi.org/10.3390/app10176012

Publisher's Note Springer Nature remains neutral with regard to jurisdictional claims in published maps and institutional affiliations. 